THE RELATIONSHIP BETWEEN THE BUILT ENVIRONMENT, PARENTAL PERCEPTIONS OF TRAFFIC SAFETY AND WALKING ENVIRONMENT, AND CHILDREN'S SCHOOL TRAVEL BEHAVIOUR IN TORONTO

\author{
by \\ Amarpreet Guliani, \\ B.Arch, GND University, 1999 \\ A Major Research Paper \\ presented to Ryerson University \\ In partial fulfilment of the requirements for the degree of \\ Master of Planning \\ In \\ Urban Development \\ Toronto, ON, Canada, 2014
}

(C)Amarpreet Guliani, 2014 


\section{Author's Declaration}

I hereby declare that I am the sole author of this major research paper. This is a true copy of the major research paper, including any required final revisions, as accepted by my examiners. I authorize Ryerson University to lend this major research paper to other institutions or individuals for the purpose of scholarly research I further authorize Ryerson University to reproduce this major research paper by photocopying or by other means, in total or in part, at the request of other institutions or individuals for the purpose of scholarly research. I understand that my major research paper may be made electronically available to the public. 


\title{
THE RELATIONSHIP BETWEEN THE BUILT ENVIRONMENT, PARENTAL PERCEPTIONS OF TRAFFIC SAFETY AND WALKING ENVIRONMENT, AND CHILDREN'S SCHOOL TRAVEL BEHAVIOUR IN TORONTO
}

(C) Amarpreet Guliani, 2014

$$
\text { Master of Planning }
$$

In

Urban Development

Ryerson University

\begin{abstract}
Decline in children's participation in active school transportation (AST) has drawn attention of those concerned with children's health and wellbeing. Recent researcher has shown links between built environment, individuals' psychological and social behaviour, and AST. However, no known research has empirically evaluated their hypothesized relationship simultaneously. This study explored the association between the built environment, parental perceptions of traffic safety and walking environment, sociodemographic characteristics, and AST. Structural equation modeling was employed to quantitatively analyse data on 720 students and their parents, collected from 16 elementary schools in Toronto, Ontario. Findings of this study add new knowledge to the existing literature. Parental perception of the neighbourhood walking environment was found to play a noteworthy role; but the perception of traffic safety had no effect on children's odds of walking to school. Additionally, dissonance was found between parental subjective views and the objective built environment characteristics. Evidently, AST mode choice is a multilevel and complex process. Suggested improvements include development of new school level programs founded in new City-level children specific policies. Keywords: Active school transportation, children, parental perceptions, traffic safety, walking environment, planning.
\end{abstract}




\section{Acknowledgements}

The completion of this major research paper is due to generous contribution of many

individuals. My research supervisor, Dr. Raktim Mitra, provided vital guidance and support throughout the process, without which my research would not have been possible. I would like to thank Dr. Ron Buliung at the Department of Geography, University of Toronto, Mississauga, for making the Project BEAT data available, evaluating, and providing valuable feedback as a second reader.

The opportunities and experiences offered by the Urban Planning program at the School of Urban and Regional Planning have been richly rewarding. In addition to my research supervisor, I would like to express my gratitude to Dr. Christopher De Sousa and entire faculty members for their direction, assistance, and encouragement.

My family has always been incredibly supportive. Thanks to my parents, wife, and children, without their encouragement I would have never followed this path.

Thank you. 


\section{Table of Contents}

Abstract $\quad$ iii

List of Figure vi vi

List of Tables $\quad$ vi

List of Appendices $\quad$ vi

ChAPTER 1: INTRODUCTION $\quad 1$

$\begin{array}{lll}1.1 & \text { Research Problem } & 2\end{array}$

1.2 Document organization 3

Chapter 2: Literature Review $\quad \mathbf{4}$

2.1 Theoretical Foundation of Research on Active School Transportation 4

2.2 Correlates of Children's Active School Transportation 9

$\begin{array}{lll}2.3 & \text { Research Gap } & 11\end{array}$

Chapter 3: Study Design $\quad 13$

\begin{tabular}{lll}
\hline 3.1 & Conceptual Analysis Framework & 13
\end{tabular}

3.2 Data $\quad 14$

$\begin{array}{lll}3.3 & \text { Research Variables } & 16\end{array}$

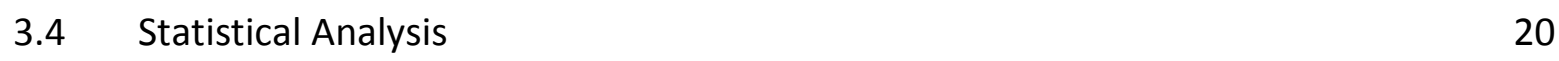

3.5 Model Specification 23

Chapter 4: Results $\quad 25$

4.1 Data Description $\quad 25$

$\begin{array}{lll}4.2 & \text { Model Fit } & 27\end{array}$

4.3 Model Results and Interpretations $\quad 28$

$\begin{array}{lll}4.4 & \text { Discussion } & 33\end{array}$

$\begin{array}{lll}4.5 & \text { Summary of the findings } & 37\end{array}$

Chapter 5: IMPlications for Policy $\quad 38$

\begin{tabular}{lll}
\hline 5.1 & Review of existing policy framework & 38
\end{tabular}

$\begin{array}{lll}5.2 & \text { Recommendations } & 40\end{array}$

\begin{tabular}{lr} 
Chapter 6: CONClusion & $\mathbf{4 5}$ \\
\hline
\end{tabular}

\begin{tabular}{lll}
\hline 6.1 & Limitations & 45
\end{tabular}

$\begin{array}{ll}\text { REFERENCES } & 49\end{array}$ 


\section{List of Figures}

Figure 2.1: A behavioural model of school transportation. Image Source: Mitra, (2013)

Figure 3.1: Conceptual Analysis Framework

(Adapted from the BMST framework by Mitra, 2013)

$\begin{array}{lll}\text { Figure } 3.5 & \text { Hypothesized Model } & 24\end{array}$

$\begin{array}{lll}\text { Figure 4.4: } & \text { Final Model Outputs } & 31\end{array}$

$\begin{array}{lll}\text { Figure A.1 } & \text { Model Outputs-For Boys } & 47\end{array}$

$\begin{array}{lll}\text { Figure A.2 } & \text { Model Outputs-For Girls } & 48\end{array}$

\section{List of Tables}

$\begin{array}{lll}\text { Table } 4.1 \quad \text { Descriptive Statistics } & 26\end{array}$

$\begin{array}{lll}\text { Table } 4.2 & \text { Principal Component Analysis } & 27\end{array}$

$\begin{array}{lll}\text { Table } 4.3 \quad \text { Model Fit Measure } & 28\end{array}$

\section{List of Appendices}

Appendix ' $A$ ' Additional Model Outputs 


\section{Chapter 1: Introduction}

Active Transportation is the engagement in physical activity (PA) for making trips using one or several human-powered modes of transportation such as walking or cycling (Sallis et al., 2004; PHAC, 2013). Many studies have highlighted that PA, as structured exercise or unstructured movement and play, not only improves children's physiological health, but also enhances their cognitive abilities (Tomporowski et al., 2008; Bürgi et al., 2011). Furthermore, the belief is that children who acquire patterns of PA at a younger age are more likely to carry forward this healthy lifestyle and its benefits over their life span (Sylvia-Bobiak \& Caldwell, 2006; Thompson et al., 2008).

Guidelines in Canada recommends 60 minutes of moderate-to vigorous-Intensity physical activity (MVPA) a day for children and youth (CSEP, 2011), which can be achieved through combinations of playful and recreational activities, physical education activities, and active transport. Active school transportation (AST), i.e. walk, cycle, skate, and skateboard etc. to and from school, is an important contributor to the recommended daily physical activity levels for children and youth (Sirard \& Slater, 2008). From a study conducted in 2006 in Derby (UK) on a large number of school going children, Daly-Smith et al (2011) assert that children's AST contributes to $18.4 \pm 16.4$ minutes of MVPA per day. Similarly, in a research conducted in Bristol (England), Southward et al. (2012) found that AST contributes to $33.7 \%$ of daily requirement of MVPA. Research also indicates that these trips can add to a child's social interaction activity for the day (Cooper et al., 2003; Metcalf et al., 2004). On the other hand, children with sedentary lifestyle are prone to overweight and obesity, which increases the risk of a number of adverse health conditions including Type 2 diabetes (Al Mamun et al., 2009), 
high cholesterol levels, cardiovascular complications (Thompson et al., 2007; Siervo et al., 2012), and unfavourable musculoskeletal conditions (Haukka et al., 2012).

Despite of the stated benefits of PA and AST and the risks of sedentary behaviour, majority of Canadian children and youth are still considered insufficiently active to enjoy its long-term health benefits; only 7\% of which are meeting current guidelines (AHKC, 2012). With regard to AST uptake, a recent study in the Greater Toronto Area suggests that between 1986 and 2006, walking to school has declined from $53 \%$ to $42 \%$ for ages $11-13$, and from $39 \%$ to $31 \%$ for ages 14-15 (Buliung et. al, 2009). The decline in AST levels has consequences for the environment and health; thus improving AST participation in children and youth is important for the future health of younger population.

\subsection{Research Problem:}

Urban planners, researchers from public health field, and practitioners believe that built environment plays a major role in facilitating AST. Consequently, a large number of studies have investigated association of neighbourhood built environment with children's school travel behaviour. Recent research has conceptualized that the built environment informs parental perceptions of the neighbourhood environment, which impact household decisions related to a child's school travel mode (McMillan, 2005; Mitra, 2013). However, no known study has empirically examined these hypothesized relationships between the objectively measurable built environment features, parental perceptions, sociodemographic characteristics, and AST in a single study. Integrating and examining all these factors into a single study would not only help testing a conceptual research framework, but is also methodologically important. It eliminates confounding results by controlling for other variables while investigating the effect 
of one factor. For example, controlling for household level characteristics would allow examining the correlation of built environment features and parental perceptions on the rates of AST under different sociodemographic conditions. Additionally, an advanced understanding of the link between built environment and individuals' psychological and social behaviour is necessary to develop policy level interventions that promote AST.

This study used Mitra's (2013) Behavioural Model of School Transportation framework as guideline to examine school travel behaviour amongst young children. Using structural equation modelling technique to the data collected from Toronto, Canada, this study aimed to address following research question:

What is the relationship between the built environment and parental perceptions of the traffic safety and neighbourhood walking environment, as they relate to children's school travel behaviour?

Based on Toronto specific findings, the study recommended changes to the City policies and interventions that would prove helpful in changing children's school travel behaviour.

\subsection{Document organization}

This paper is divided into six chapters. Chapter one serves as an introduction to the topic stating the importance and purpose of current study and research problem. The second chapter provides a literature review of the theoretical approaches towards children's AST and highlights research gaps. Chapter three describes research design, data, study variables, and statistical analysis approach. The fourth chapter discusses results and interpretations. Fifth chapter recommends policy level interventions. Sixth and final chapter draws conclusion and states limitations of this study. 


\section{Section 2: Literature Review}

Research on the determinants of children's Active School Transportation (AST) has grown rapidly during the past five years. Studies on the active transportation behaviour have employed variety of approaches to understand patterns of children's school travel mode choice (Mitra, 2013). An understanding of the theoretical perspectives and various determinants, within which AST has been explored in the past, is necessary to suggest future interventions.

\subsection{Theoretical Foundation of Research on AST}

Transportation/urban planning has explored "non-motorized transport", in the form of walking and cycling, for utilitarian purposes in the early studies (Sallis et al., 2004). Early research from this field was largely based on the consumer choice theory framework, where travel choice decisions are rationalized by economic way of thinking i.e. to maximize trip utility (Mitra, 2013). Mainly driven by the need to reduce auto use and pollution, the early studies assumed that neighbourhood design and land use affects active transportation behaviour by contributing to the utility of a trip. Early transportation models have explored impact of proximity (e.g. distance, land use density and mix) and route directness (e.g. destination connectivity), within the consumer choice theory framework (Cervero and Kockelman, 1997; Sallis et al., 2004). However, realizing that urban environment cannot solely explain the decline in active transportation behaviour, some researchers from transportation/urban planning field have also explored relationship between attitude/preference, cognitive processes, and active travel mode choice (Cao et al., 2009; Ewing \& Cervero, 2010).

As consumer choice theory is limited in completely explaining the aspects of behavioural process (Walker, 2001), many researchers have frequently drawn upon the theory of planned 
behaviour (Cao et al., 2009; Handy et al., 2006), and human activity theory framework (Bhatt \& Koppelman, 2003; McDonald, 2008; Mitra, 2013), to explore walking and/or cycling. The application of these theories in explaining rates of active transportation has remained limited due to their conceptualization and non-availability of data at the appropriate level (Mitra, 2013).

In regards to active transportation, research from the public health field shifts focus from the economic aspects of the trip attributes. It rather examines relationship of individual's psychological and social behaviour and environmental variables (Sallis et al., 2004; Mitra, 2013). The environment is defined as "anything outside the individual" that can affect physical activity and active transportation including social as well as physical environmental factors (Ferreira et al., 2007). Studies from the public health field are largely drawn on the social cognitive theory (SCT) and the social ecological model (Glanz et al. 2008). According to the SCT, an individual's behaviour is informed by his/her psychosocial and physical capabilities, perception of the environment, and cognitive learning through observation (Bandura, 1986). The SCT predicates on the concept of Reciprocal Determinism, according to which an individual can be both facilitator and responder to a change. Thus, changes in the environment can promote healthier behaviour such as active transportation. However, the theory assumes that environmental changes will automatically result in changes to the person, which may not always be true. Moreover, the SCT appears to be limited in scope with regards to number of variable and ignores biological inabilities.

Recent studies from transportation/urban planning and health fields appear to have adopted collaborative approaches. Transportation/urban planning researchers have started exploring 
health benefits of AST, whereas there is growing interest in exploring environment correlates amongst health researchers (Sallis et al., 2004). Common to both fields, the social ecological models have helped better understand the effects of built environment on the active transportation and physical activity behaviour (Sirard \& Slater, 2008). The social ecological models can not only adapt to many aspects of the human behaviour, but also allow to analyze various correlates that exist at multiple levels (Mitra, 2013). These include household, individual, sociodemographic, and sociocultural and physical environment (Sallis et al., 2008; Giles-Corti \& Donovan, 2003). Given the robustness of social ecological models, many of the recent studies on AST are based on this framework.

Building on the social ecological model, McMillan (2005) proposed a framework, which hypothesizes that parents are the central actors in making mode choice decisions for AST. McMillan (2005) postulates that participation in AST is explained by the interaction between urban form (e.g. distance from home to school, intersection density, street network connectivity, active transportation infrastructure, land use mix, parks and other facilities along the way to school), mediating factors (i.e. perceptions, beliefs, and attitudes), and moderating factors (sociodemographic and social/cultural norms e.g. age, gender, number of children at home, parents' attitudes) that exist at different spatial levels. The parents first process the characteristics of the urban form that indirectly influence their perceptions, beliefs (mediating factors), which interact with moderating factors in sorting the final decision about AST mode choice for their children. However, McMillan (2005) conceptualized the framework specifically for elementary school children. 
Panter et al. (2008) has proposed a comprehensive approach to examine factors that influence children's AT decision making process. Panter et al. (2008) argue that children's AST mode choice is influenced by four categories of environmental correlates: physical environment (characteristics of the neighbourhood, destination, and the route), household and individual factors (sociodemographic, parental attitudes and perceptions, youth's attitude and perceptions), external factors (weather, policies, cost of travel), and main moderators (age, gender, distance to destination). Although framework by Panter et al. (2008) greatly adds to the AST research by hypothesizing that both children and parents negotiate in make children's AST mode choice, but it doesn't clearly explain how environmental correlates are interlinked in the context of behavioural processes (Mitra, 2013). Based on the activity-travel framework, research from Copperman \& Bhatt (2010) and McDonald (2008) suggests that parents' work related travel needs (e.g. route, distance, schedule, mode of transportation to work), influence their decision to either escort or allow their children to independently travel to school. Children who are escorted by their parents are more likely to be driven to and/or from school (Copperman \& Bhatt, 2010; McDonald, 2008). However, their research does not explicitly account for the influence of factors related to the built environment, parental perceptions and attitudes, and governmental policies etc.

Most recently, Mitra (2013) has proposed the behavioural model of school transportation (BMST) to explain determinants of independent mobility and AST mode choice (Figure 2.1). Like previous studies, the BMST builds on the social ecological model, i.e. AST mode choice is influenced by factors at multilevel: urban environment, household and youth/child's characteristics, and external influences such as natural environment and policy context. 
However, it adds to the existing AST research by combining those multilevel factors with activity-travel framework.

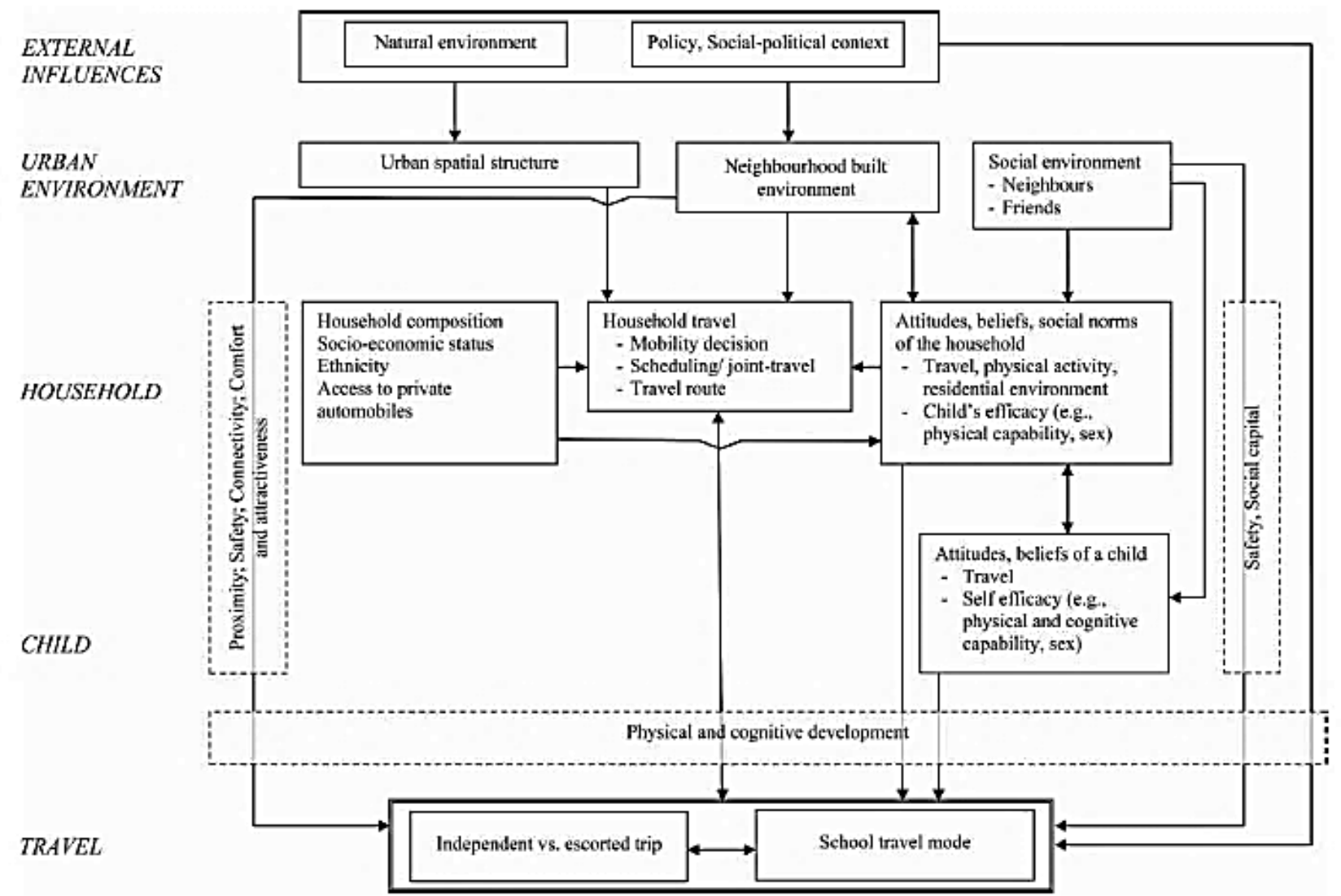

Figure 2.1: Behavioural Model of School Transportation. Source: Mitra (2013)

The BMST emphasizes that both parents and children negotiate in the AST mode choice decision making process, however, parents take central role in deciding between independent or escorted trip and mode choice based on their perception about neighbourhood's built environment, child's cognitive ability to make a safe trip, their attitude towards active transportation, availability of personal vehicles, and activity constraints such as conflict between school timings and work schedule. The BMST extends McMillan (2005) model by suggesting that neighbourhood's built environment (both built and social) influences parents' 
perceptions through five domains: Proximity, Safety, Connectivity, Comfort, and Attractiveness. However, the nature and direction of the conceptualized relationships in the BMST remains understudied.

\subsection{Correlates of Children's Active School Transportation (AST)}

A large volume of scholarly research, with and without an explicit theoretical foundation, has attempted to explain various variables of AST. Findings from this literature are summarized below:

\section{Urban Environment Variables:}

Existing studies have found strong correlation between the distance from child's home to school and AST rates. The likelihood of children to walk to school reduces with increase in the distance (Babey et al., 2009; McDonald, 2008; Mitra \& Buliung, 2012; Panter et al., 2010a).

Some researchers have found positive association between street network connectivity and AST (Dalton et al., 2011; de Vries et al., 2010; Kerr et al., 2006; Panter et al., 2010a). On the contrary, others have reported higher street network connectivity resulting in reduced AST rates (Larsen et al., 2012; Mitra et al., 2010; Schlossberg et al., 2006) probably due to perceived safety risk from increased traffic volume (Giles-Corti et al., 2011; Sirdad and Slater, 2008).

Presence of active transportation infrastructure (sidewalks, pedestrian crossings, cycle routes, controlled traffic crossings) was found to be associated with ATS (Cao et al., 2009; Timprio et al., 2006).

On the other hand, streets with high traffic and busy intersections may raise traffic and personal safety concerns, whereby discouraging AST rate (Giles-Corti et al., 2011; Mitra et al., 2010, Schlossberg et al., 2006). 
Studies analyzing the impact of land use mix on AST rates have remained inconclusive (Mitra, 2013). Larsen et al. (2009) and McMillan (2007) found mixed-use neighbourhoods to associate with walking, while Ewing et al., 2004 and Mitra et al., 2010; have indicated to the contrary. In the social context of built environment, neighbourhoods with high population density (Dalton et al., 2011; Kerr et al., 2006; Lin \& Chang, 2010; McDonald, 2008; Nelson et al., 2008) are found to be associated with have high rates of AST. Compact and dense neighbourhoods, which are perceived as walkable, facilitate large population of children to live close to school; thus are more likely to have high AST rates (Stewart, 2011; Dalton et al., 2011; Mitra et al., 2010, Panter et al. 2010a). However, no causal relationships have been established in this context so far.

\section{Perceptions and attitudes:}

The findings from the research on whether neighbourhood safety perceptions (related to traffic, environmental hazards, crime and incivilities) affects AST have been largely mixed (Rossen et al., 2011). Many studies have found a negative correlation between perception of personal and traffic safety and AST rate (Bringolf-Isler et al., 2008; Lang et al., 2011; Panter et al., 2010b; Timperio et al., 2006). Concern about general safety rather than neighbourhood crime rate was more often associated with AST (Stewart, 2011).

Multiple studies have reported a household's attitude towards active transportation as a prime factor that positively influences AST rate. Parents who consider car as more convenient and socially acceptable mode of transportation were found to be wheeling their children to school (Faulkner et al., 2010; Lang et al., 2011; Panter et al., 2010b). However, environmentally conscious families were found to promote AST (Black et al., 2001). Parents' confidence in their child's ability to make a safe trip to school was also found to be positively associated with AST 
(Emond \& Handy, 2012; Lang et al., 2011; Wen et al., 2008). Similarly, parents who understood importance of child's social interaction were more likely to allow their children to walk or bike to school (Emond \& Handy, 2012; McMillan, 2007; Timperio et al., 2006).

\section{Sociodemographic Characteristics:}

The results from studies on the sociodemographic characteristics and AST rate have been mixed, partially reflecting heterogeneity in the study populations. For example, some researchers have observed child's sex to be associated with AST (Larsen et al., 2009; McDonald, 2008), whereas other studies have reported contrary findings (Black et al., 2001, McDonald 2008, Mitra et al., 2010). Similarly, some studies have found association between the low household income and AST rate (McMillan, 2007; Wilson et al., 2010), while other studies have not found any correlation between socioeconomic variables and travel outcome for children's AST (McDonald, 2008; Timperio, 2006).

A significant negative association between household's access to automobile and ATS was reported by a large number of studies (Pont et al., 2009; Timperio et al., 2006). This might also be due to schedule constrains that limit transportation options, or convenience of parents in dropping their children to school while driving to work or other locations (Stewart, 2011). However children owing a bike are likely to make more cycle trips than who do not.

\subsection{Research Gap}

As discusses in the literature review section, a large number of studies have found correlation between the built environment (objectively measured or perceived), and household and individual characteristics (sociodemographic variables) with the mode choice behaviour. Some researchers (e.g. McMillan, 2005; Panter et al., 2008; Mitra, 2013) have theoretically explained 
the influence of built environment (objectively measured or perceived) on parents' perceptions. For example, Mitra's (2013) BMST framework hypothesizes that greater intersection density and busy intersection crossing (both variables of the urban environment) directly correlate with parents' perception of traffic safety, which in return impacts their child's AST mode choice. However, no known research has empirically examined these hypothesized relationships in a single study simultaneously. It remains unknown how parental perceptions of neighbourhood environment mediate the relationship between the built environment and AST. 


\section{Chapter 3: Study Design}

\subsection{Conceptual Analysis Framework}

Using Mitra's (2013) Behavioural Model of School Transportation (BMST) framework as a guideline, this study specifically focused on the relationship between seven neighbourhood environment variables, one of BMST's five domains: Safety (in the form of two latent parental perceptions: perceptions of the traffic safety and neighbourhood walking environment), and five sociodemographic level variables, as they relate to the decision between walking versus driven in private vehicle to school. To reiterate, the BMST theorizes that both parents and children negotiate in the active school transportation (AST) mode choice process, which is impacted by multilevel factors: urban environment, household and youth/child's characteristics, and external influences (natural environment and policy context). However, for young children, parents take central role in deciding their child's school travel mode choice, based on their perceptions of the neighbourhood's built environment, child's cognitive ability to make a safe trip, their attitude towards AST, availability of personal vehicles, and activity constraints such as conflict between school timings and work schedule (Mitra, 2013).

Given the scope of this study, figure 3.1 demonstrates the conceptual analysis framework adapted from the BMST framework. The arrows between the factors indicate hypothesized direction of association as theorized by the BMST. Parental perceptions were not directly observed but were rather inferred from parents' responses in the study data; therefore they were latent in nature. Section 3.3 describes details of all aforementioned research variables. 


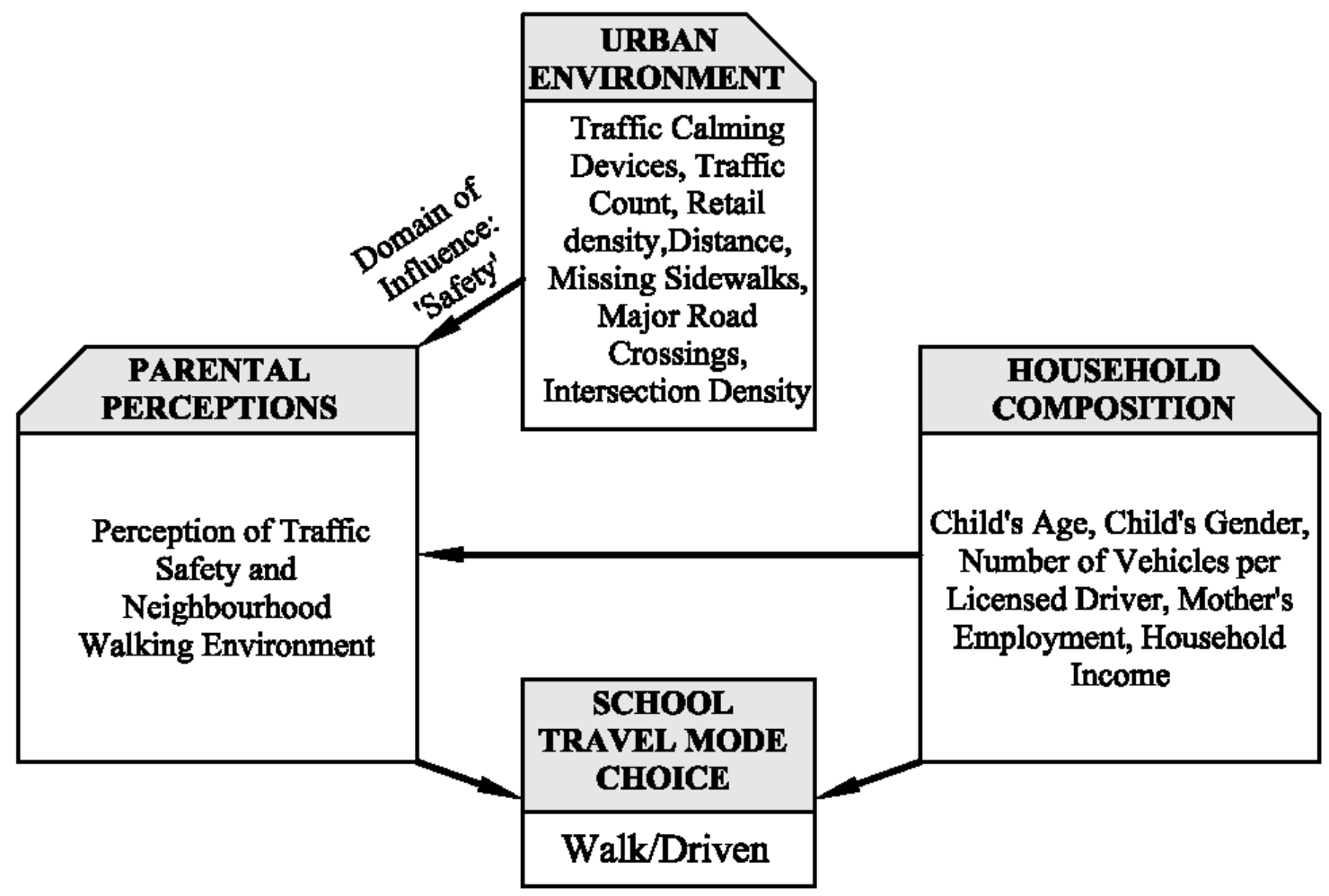

Figure 3.1: Conceptual Analysis Framework (adapted from the BMST framework by Mitra, 2013)

\subsection{Data}

To test the hypotheses of the conceptual analysis framework, this study utilized data collected through the Project BEAT (Built Environment and Active Transportation) that took place in Toronto during fall 2010 and spring 2011. The Project BEAT is a large scale multidisciplinary and mixed method examination that involved grade 5 and 6 students and their parents. One of the main objectives of the Project BEAT is to examine the relationship between the built environment and children's school travel behaviour. Given Toronto's historical and political context, variety in the built environment, transportation options, land use, and social characteristics amongst neighbourhoods, allowed the project team to control which schools to study (BEAT, 2010). 
In January 2010, the Project BEAT team sent invitations to all elementary schools $(n=435)$ within Toronto School Board District. From the group of interested respondents, eight central city schools located within neighbourhood surrounding the downtown core, and eight inner suburb schools located within relatively recent neighbourhoods were selected to ensure variability in the built environment and SES characteristics. Grade 5 and 6 students and their parents completed a survey containing set of questions and map of their typical route to and from the school. Questions in the survey were intended to gain knowledge about child and parents' perceptions of safety and built environment of their neighbourhood, parents' activity pattern, parents' attitude towards AST, and sociodemographic characteristics of the household. A total of 1,027 students (and their parents) took part in the survey. For the purpose of this study, final data set from the Project BEAT was further screened to eliminate any missing data, unengaged responses, and univariate outliers. Drawing on previous research, this study hypothesizes that walking will not be a feasible mode of transportation for young children living at a distance greater than 2 miles $(3.22 \mathrm{~km})$. Therefore, observations with travel distance greater than 2 miles $(3.22 \mathrm{~km})$ were removed. Additionally, the scope of this study was limited to examining only two modes of school travel-walking or driven in a private automobile -largely due to methodological limitations and inadequacy of sample size for other modes. Therefore, observations for other modes such as ride a bicycle $(n=19,2.1 \%)$, school bus $(n=15,1.7 \%)$, and public transit $(n=9,1 \%)$ were also dropped from the final data set. After these adjustments, the final data includes $n=720$ data points. 


\subsection{Research Variables}

\subsubsection{Dependent Variable:}

The scope of this study was limited to examining only two modes of school travel: walking or driven in a private driven automobile (0_Driven, 1_Walk).

\subsubsection{Objectively Measured Built Environment:}

This study explored built environment along a child's home-to-school route. The conceptual analysis framework (figure 3.1) suggests that built environment influences mode choice indirectly by correlating with parental perceptions. Giles-Corti et al. (2011) posit that certain built environment features of the neighbourhood contribute towards traffic volume, which might influences parents' perception of pedestrian and traffic safety on the route to school. To understand this relationship, this study included both built environment and traffic environment variables into the analysis.

Initially, eight school route based built environment variables were measured objectively, using ArcGIS software, by intersecting the Project BEAT's route to school data with the City of Toronto's data on railway crossing, major roads, missing sidewalk, traffic calming devices, and intersections. The rationale for variable section and the approaches used to compute them are discussed as below:

Traffic calming devices: This study assumed that traffic-calming devices such as chicanes, speed bumps, raised intersections, gateways, raised crosswalks, and traffic circles are conducive to walking by increasing pedestrian and traffic safety. A binary variable was included in this study, which identified respondents having at least one traffic calming device installed on their route to school. 
Traffic Counts: Researchers analyzing traffic and school travel have reported a correlation between the traffic volume around the school and safety (Collins \& Kearns, 2002; Giles-Corti et al., 2011; Schlossberg et al., 2006). Drawing on previous studies, this study assumed that parents perceive their child's exposure to high volume as a risk to pedestrian and traffic safety. The study included morning traffic counts around school, which were observed by the Project BEAT team.

Retail Density: Previous studies that analyzed the impact of land use mix have remained inconclusive (Mitra, 2013). Larsen et al. (2009); McMillan (2007) found mixed-use neighbourhoods to associate with walking, while Ewing et al., (2004); Mitra et al., (2010) have indicated to the contrary. To explore the influence of land use mix on children's school travel behaviour in Toronto, this study included a retail density variable consisting of number of retail units per route kilometer.

Distance to school from home: Existing literature confirms that distance of home to/from school is the clearest correlate of children's travel behaviour. Children's odds of walking to school decrease with increase in distance from home to school (Babey et al., 2009; McDonald, 2008; Mitra \& Buliung, 2012; Panter et al., 2010a). Drawing on previous research, this study hypothesized that distance between child's home and school is negatively correlated with chances of walking to school. A variable with length of the route to school that was measured in the Project BEAT was used for final analysis.

Railway track: This study assumed that parents could perceive an active railway crossing on route a major barrier and a potential pedestrian safety risk for their child. Consequently, presence of railway tracks on the route to school would decrease the likelihood of parents to 
allow their elementary school child to walk to school. A binary variable was included in this study, which identified respondents who had to cross railway track on the way to school.

Missing sidewalks: Existing literature reveals that presence of active transportation infrastructure (sidewalks, pedestrian crossings, cycle routes, controlled traffic crossings) is found to be associated with walking (Cao et al., 2009; Timprio et al., 2006). This study assumed that the absence of sidewalk on the way to school presents a pedestrian safety risk and discourages walking. A variable with length of missing sidewalk per school route kilometer was included in this study to reflect objectively measured active transportation infrastructure.

Major road crossings: Major roads generally carry high volume of fast moving traffic, which could be perceived as risk to pedestrian safety (Giles-Corti et al., 2011; Mitra et al., 2010, Schlossberg et al., 2006). This study assumed that overlapping of school route with major road hinders walking; thus a variable containing length of major road per school route kilometer, representing objectively measured overlap, was included in the analysis.

Intersection density: Existing literature demonstrates that higher number of intersections warrant a well-connected street network, which is found to be positively associated with walking by some researchers (Dalton et al., 2011; de Vries et al., 2010; Kerr et al., 2006; Panter et al., 2010a). On the contrary, others have found higher street network connectivity resulting in reduced walking rates (Larsen et al., 2012; Mitra et al., 2010; Schlossberg et al., 2006) probably due to perceived safety risk from increased traffic volume (Giles-Corti et al., 2011; Sirard \& Slater, 2008). This study assumed that intersection density promotes traffic volume and negatively influences parents' perception of traffic safety. A variable with objectively 
measured number of intersections per school route kilometer was included in this study for further analysis.

Binary logistic regression between each of the eight objectively measured built environment variables and walking (versus being driven in car) was performed. Presence of Railway Track on route was not associated with walking at 0.1 level of significance; therefore it was dropped from further analysis.

\subsubsection{Parents' Perceptions of Neighbourhood Environment}

This study explored parents' response to seven statements, reflecting their perceptions of traffic safety and walking environment, in the Project BEAT survey. The statements asked parents whether they agree or disagree on a 5-point scale from 1 as "Strongly Agree" to 5 as "Strongly Disagree". A binary logistic regression was performed between walking (versus being driven in car) and each of the statements. One statement "There are enough crosswalks or traffic lights to help walkers cross busy streets" was not associated with walking at 0.1 level of significance; thus was dropped from the multivariate analysis. To identify conceptually meaningful environmental perceptions out of remaining six responses, a principal component analysis with Promax rotation (which assumes the factors are uncorrelated) was performed using SPSS software. Two clear factors emerged a) Perception of traffic safety b) Perception of neighbourhood walking environment. Table 4.2 shows factor loadings for each statement. For descriptive data analysis, responses in final data set were collapsed into two groups 'Agree' (1 or 2 on the 5-point scale) and 'Neither agree nor disagree/disagree/strongly disagree' ( 3 to 5 on the 5-point scale). For Multivariate analysis, two new variables 'Traffic Safety' and 
'Walking Environment', reflecting parental perceptions, were created using factor loadings described in table 4.2 .

\subsubsection{Sociodemographic Variables}

This study used sociodemographic information collected through the Project BEAT survey. Informed by the existing literature, five key sociodemographic variables were included in the analysis: child's age, child's gender, number of vehicles available per licensed driver, mother's employment status, and median household income. A number of respondents did not provide individual level household income data. To rectify the problem, year 2010 median household income data at the dissemination area (DA) level (geographical area smaller than neighbourhood scale) collected by the Statistics Canada (CHASS, 2013) was used. A child's area of residence was classified as a low-income when the DA-level median household income was less than median income for the City of Toronto (i.e. CAD 43,291; Statistics Canada, 2013). A binary logistic regression was performed on each of the sociodemographic variables and the walking (versus driven to school), all of them were found to be statistically significant at 0.05 level of significance; thus were included for further analysis

\subsection{Statistical Analysis}

Since the objective of this study was to integrate and analyse multilevel correlates of AST (i.e. neighbourhood built environment, parental perceptions, and sociodemographic variables) at once, Structural Equation Modelling (SEM) approach was used for that purpose. The SEM is an extension of multivariate regression analysis that allows statistically testing the hypothesized model to simultaneous analyze the entire system of endogenous and exogenous variables and determine the extent to which hypothesized model is consistent with the data (Byrne, 2010). 
The SEM was preferred over other approaches for flexibility, comprehensiveness in testing formally specified models, and subsuming many other techniques such as multiple regression and ANOVA. In a typical hypothesized model in SEM, endogenous variables are the dependent variables that are generated within the model (parental perceptions of the built environment and the mode choice i.e. walking/ driven in a private vehicle). Exogenous variables, on the other hand, do not depend on any other variable included in the model, i.e. they come from the 'outside' of the model, (built environment and sociodemographic variables).

SEM allows computing latent factors for unobserved variables such as perceptions. Since all of the endogenous and exogenous variables were either observed during Project BEAT data collection or computed using principal component analysis of observed variables, current study uses observed endogenous variable approach as explained by Mueller (1996):

$$
Y=B Y+\Gamma X+\zeta,
$$

Where

$Y=\left(N_{Y} X 1\right)$ column vector of endogenous variables $\left(N_{Y}=\right.$ number of endogenous variables $)$, $X=\left(N_{X} X 1\right)$ column vector of exogenous variables $\left(N_{X}=\right.$ number of exogenous variables $)$, $B=\left(N_{Y} X N_{Y}\right)$ matrix of coefficients representing the direct effects of endogenous variables on other endogenous variables, $\Gamma=\left(N_{Y} X N_{X}\right)$ matrix of coefficients representing the direct effects of exogenous variables on endogenous variables, and, $\zeta=\left(N_{Y} \times 1\right)$ column vector of errors.

Estimates of SEM are performed using covariance analysis method, the objective of which is to minimize the observed and estimated covariance. The direct effects in the SEM are given by 
parameter $B$ and $\Gamma$ matrices and can be interpreted in a same way as a regression coefficient (Kaplan, 2000). For any SEM model the total effects of the exogenous variable on the endogenous variables $(\mathrm{I}-\mathrm{B})^{-1} \Gamma$ and the total effects of the endogenous variables on one another are given by $(\mathrm{I}-\mathrm{B})^{-1}-\mathrm{I}($ Golob, 2003). The indirect effects are given by the differences between the total and direct effects.

This study employed AMOS (v.21) software and commonly used in practice, the maximum likelihood estimation (MLE) approach, for multivariate regression analysis of the hypothesized model. Theoretically, for estimates of the variance of parameters to be consistent, the MLE approach assumes multivariate normality in variables included in the SEM. To test for departures from normality in the study data, the Mardia statistic, which measures multivariate kurtosis with variables in their original form, was reviewed. Mardia statistic was observed as 57.07; with a critical ratio of 33.91 (a critical ratio above 1.96 signifies departure from multivariate normality with $95 \%$ confidence). In the light of these observations, three objectively measured variables with high kurtosis values were identified. To remove nonnormality in these variables, some extreme observations were removed from the data. However, this approach was discarded as it did not completely remove the non-normality. Literature on SEM reveals that meeting multivariate normality condition is a problem in many studies. Bentler and Dudgeon (1996) assert that normality assumption will often be incorrect in practice. Anderson and Amemiya (1988) and Lei and Lomax (2005) argue that large sample size in the MLE approach reduces the influence of non-normality in the data. According to Stevens (1996) for a sample size to be considered large, the ratio between the sample size and the number of observed variables should not be less than 15. Current study model has 15 variables 
and 720 observations. As sample size in the current study fulfilled aforementioned minimum ratio $(720 / 15=48>15)$ requirement, final model was processed despite deviation from the multivariate normality assumption.

\subsection{Model Specifications}

Based on the conceptual analysis framework for this study (see figure 3.1), the SEM identified neighbourhood built environment and sociodemographic characteristics as exogenous variables, and parental perceptions i.e. Traffic Safety and Walking Environment, and mode choice i.e. walking/driven as endogenous variables. Figure 3.5 represents the final model. Presumed directions of influence were strategically added from specific exogenous variables to endogenous variables based on Mitra's (2013) BMST framework and literature review. To test the hypothesis that urban environment characteristics impact parental perceptions of neighbourhood environment, the built environment variable were allowed to directly correlate with two parental perceptions. For example, Traffic calming devices and Traffic counts around school variables were hypothesized to interact with perceptions traffic safety. Similarly, Missing sidewalks variables was only influencing perception of walking environment. Major roads crossing, Intersections Density, Retail Density, and Distance were allowed to interact with both of the perceptions. To test the model hypothesis that parents consider their child's characteristics while choosing mode of transportation to school, child's age and gender variables were allowed to influence both perception variables. 


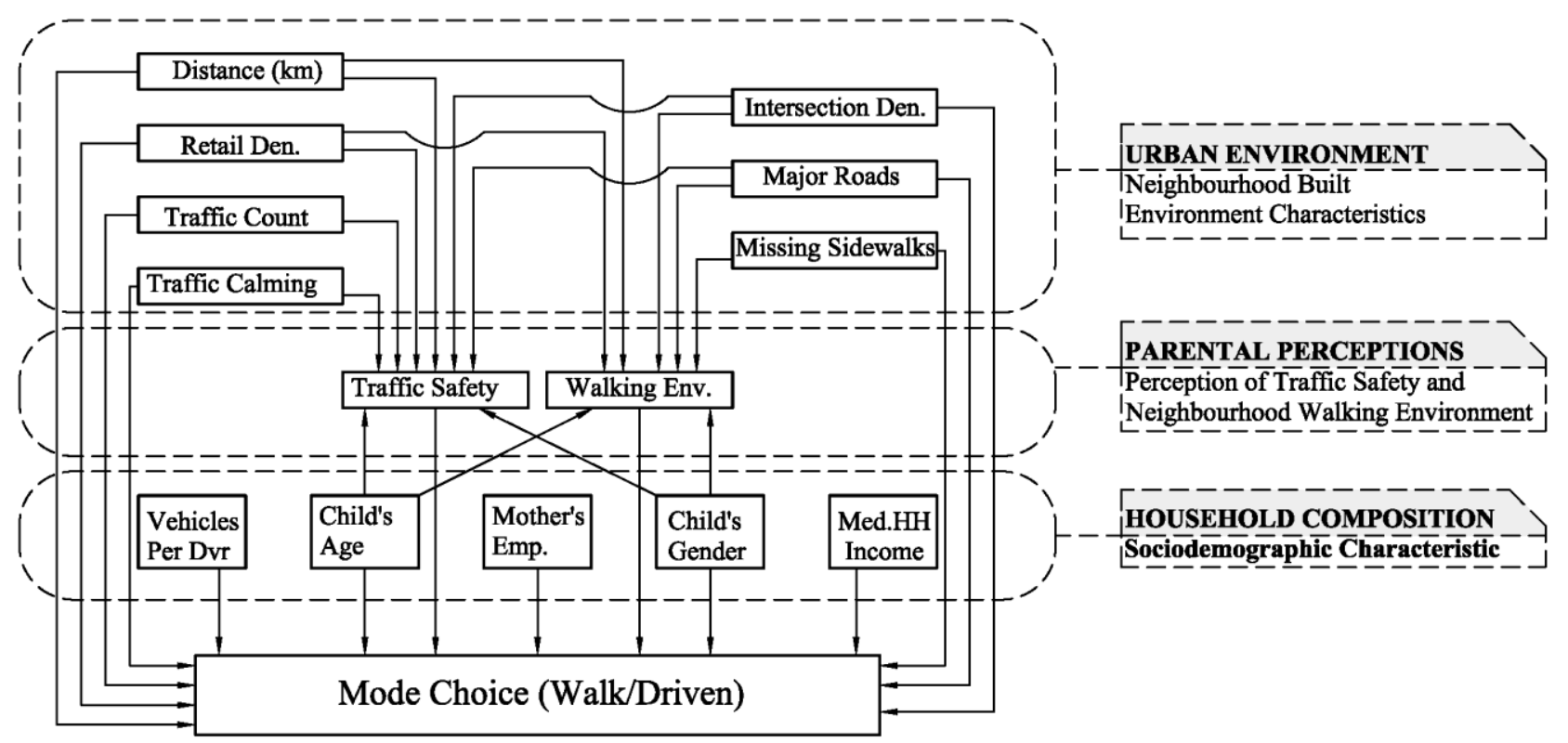

Figure 3.5: Hypothesized Model

Finally, sociodemographic, parental perceptions, the neighbourhood built environment variables were also hypothesized to directly correlate with the mode choice variable. A strong direct influence of the built environment variables would account for perhaps four remaining domains-proximity, connectivity, comfort, and attractiveness- of the BMST framework. 


\section{Chapter 4: Results}

School travel behaviour of $n=720$ grade 5 and 6 children was analysed by applying structural equation modelling approach to administrated survey responses from parents, GIS measures of built environment, and sociodemographic variables. The statistic results are summarized in table 4.1 and 4.3 .

\subsection{Data Description}

Nearly $73 \%$ of the children chose to walk to school as opposed to $26 \%$ who were driven. $52.5 \%$ surveyed children were girls and $47.5 \%$ of them were boys with an average age of 10.58 years. About $18 \%$ of the students were from low-income neighborhoods, and $82 \%$ were from highincome areas. $70 \%$ of the mothers were employed either fulltime or part-time and $30 \%$ mothers were not employed (students or unpaid). About $43.5 \%$ parents agreed that there is heavy traffic around my home. About $57 \%$ of the responding parents agreed that there is heavy traffic around child's school in the morning. Nearly $19 \%$ agreed that their child has to cross too many busy streets walking to/from school. About $48 \%$ of the parents agreed that most drives go too fast while driving in their neighbourhood. Only $10 \%$ of the surveyed parents agreed that there are not enough sidewalks in their neighbourhood. About $8 \%$ of the responding parents agreed that there are major barriers/obstacles to walking in their local neighbourhood that make it hard to get from place to place. About $22 \%$ children had traffic calming devices installed on their route to school. The median distance that a child travelled to and from school was $0.775 \mathrm{~km}$. About $41 \%$ of the students had to cross major road/s on their way to/from school. 
Table 4.1 Descriptive Statistics $(n=720)$

\begin{tabular}{|c|c|c|}
\hline Dependent Variable & & Percent \\
\hline \multicolumn{3}{|l|}{ Mode } \\
\hline Driven & & 27.4 \\
\hline Walk & & 72.6 \\
\hline Sociodemographic Variables & Mean (Std. Deviation) & Percent \\
\hline \multicolumn{3}{|l|}{ Gender } \\
\hline Girl & & 52.5 \\
\hline Boy & & 47.5 \\
\hline Age & $10.58(0.695)$ & \\
\hline Vehicles per licensed driver & $0.871(0.249)$ & \\
\hline \multicolumn{3}{|l|}{ Median Household Income } \\
\hline Above Low Income Cut-off & & 82.2 \\
\hline Below Low Income Cut-off & & 17.8 \\
\hline \multicolumn{3}{|l|}{ Mother's Employment Status } \\
\hline Part or full time Employed & & 70 \\
\hline Not Employed & & 30 \\
\hline Parental Perceptions of neighbourhood environment & & Percent \\
\hline \multicolumn{3}{|l|}{ There is heavy traffic near my home } \\
\hline Strongly Agree/Agree & & 43.5 \\
\hline Neither agree nor disagree/Disagree/Strongly Disagree & & 56.5 \\
\hline \multicolumn{3}{|l|}{ There is heavy traffic around my child's school in the morning } \\
\hline Strongly Agree/Agree & & 57.1 \\
\hline Neither agree nor disagree/Disagree/Strongly Disagree & & 42.9 \\
\hline \multicolumn{3}{|c|}{ Our child has to cross too many busy streets walking to/from school } \\
\hline Strongly Agree/Agree & & 19.3 \\
\hline Neither agree or disagree & & 80.7 \\
\hline \multicolumn{3}{|l|}{ Most drivers go too fast while driving in my neighbourhood } \\
\hline Strongly Agree/Agree & & 47.6 \\
\hline Neither agree nor disagree/Disagree/Strongly Disagree & & 52.4 \\
\hline \multicolumn{3}{|l|}{ There are not enough sidewalks } \\
\hline Strongly Agree/Agree & & 9.7 \\
\hline Neither agree nor disagree/Disagree/Strongly Disagree & & 90.3 \\
\hline \multicolumn{3}{|c|}{$\begin{array}{l}\text { There are major barriers/obstacles to walking in my local neighbourhood } \\
\text { that make it hard to get from place to place }\end{array}$} \\
\hline Strongly Agree/Agree & & 7.9 \\
\hline Neither agree nor disagree/Disagree/Strongly Disagree & & 92.1 \\
\hline Built Environment Variables & & Percent \\
\hline \multicolumn{3}{|l|}{ Traffic Calming Devices } \\
\hline Yes & & 22.1 \\
\hline No & & 77.9 \\
\hline
\end{tabular}


Table 4.1 cont.

\begin{tabular}{lcc}
\hline Built Environment Variables & Mean (Std. Deviation) & Percent \\
\hline Traffic Count around school & $580.44(523.56)$ & \\
Retail Density per route km & $6.05(14.97)$ & \\
Distance in km from house to school & $0.775(0.522)$ & \\
Missing Sidewalks per route km & $0.035(0.124)$ & \\
Major Road Crossing on route & & 41.3 \\
Yes & & 58.7 \\
No & & \\
Intersection Density per route km & $6.114(3.42)$ & \\
\hline
\end{tabular}

Table 4.2 Principal Component Analysis

\begin{tabular}{|c|c|c|}
\hline Bartlett's Test of Sphericity & 0.775 & \\
\hline Approx. Chi-Square & 1008.58 & \\
\hline p-value & 0.000 & \\
\hline \multicolumn{3}{|l|}{ Total Variance Explained } \\
\hline Cumulative Variance \% & 63.09 & \\
\hline Factor 1 Variance $\%$ & 44.94 & \\
\hline Factor 2 Variance $\%$ & 18.15 & \\
\hline Pattern Matrix & Factor 1 & Factor 2 \\
\hline There is heavy traffic near my home & 0.845 & \\
\hline There is heavy traffic around my child's school in the morning & 0.817 & \\
\hline Most drivers go too fast while driving in my neighbourhood & 0.779 & \\
\hline Our child has to cross too many busy streets walking to/from school & 0.616 & \\
\hline There are not enough sidewalks & & 0.878 \\
\hline $\begin{array}{l}\text { There are major barriers/obstacles to walking in my local } \\
\text { neighbourhood that make it hard to get from place to place }\end{array}$ & & 0.679 \\
\hline Reliability Statistics & Cronbac & \\
\hline Factor 1 & 0.786 & \\
\hline Factor 2 & 0.399 & \\
\hline
\end{tabular}

\subsection{Model Fit}

To measure the absolute model fit, three most basic indicators: ratio of the chi-square $(\chi 2)$ statistic and degree of freedom (df), the goodness-of-fit index $(\mathrm{GFI})^{1}$, and the root mean square

\footnotetext{
${ }^{1}$ - the relative proportion of variance and covariance in the sample covariance matrix explained by the model-implied covariance matrix
} 
error approximation (RMSEA) ${ }^{2}$, were analysed. The estimated model showed a good fit, as seen in Table 4.3.

First, a value of 2.70 was observed for $\chi 2 / d f$, which as a 'rule of thumb' should be less than three. Second, the GFI value was 0.975 , which showed a good fit as values closer to 1 are considered better. The RMSEA was observed as 0.049 , where values less than 0.05 indicate a good fit.

Table 4.3: Model Fit Measure

Chi Square $(\chi 2)$ 137.752

Degree of Freedom (df) 51

$\chi 2 / d f$

Good-Fitness-Index (GFI)

0.975

Root Mean Square Error Approximation

0.049

\subsection{Model results and interpretations}

The model estimation results are presented in figure 4.4. Values on the direction of influence line show direct effects between exogenous and endogenous variables (matrix gamma), and the direct effects within endogenous variables (matrix beta). Values in the parenthesis represent $p$-values. All highlighted values are statically significant (at $<0.05$ level) direct effects values.

\subsubsection{School travel mode choice and Sociodemographic characteristics}

The final model allowed testing direct and moderated effects of sociodemographic characteristics on walking (versus driven in a private vehicle). Their direct influences were largely as anticipated and consistent with existing literature. Child's gender and age was found to be significantly correlated with mode choice. Consistent with previous studies, the number

\footnotetext{
2 - measures the estimated discrepancy between the model-implied and true population covariance matrix, corrected for degrees of freedom
} 
of vehicles available per licensed driver in a household played a significant role in the mode choice. The model suggested a statistically stronger evidence of negative correlation between the number of vehicles available per licensed driver variable and mode choice in the case of girls (see appendix ' $A$ ' for gender based model outputs). No significant association was found between neighbourhood level household income, mother's employment status and mode choice.

However, indirect influence of sociodemographic variables on walking (versus driven in a private vehicle), through parents' perceptions of traffic safety and neighbourhood walking environment, was rather counterintuitive. No significant correlation was found between child's age, gender and parents' environmental perceptions.

\subsubsection{School travel mode choice and Parents' environmental perceptions}

Using Mitra's (2013) BMST framework as a guideline, this study specifically explored relationship between neighbourhood built environment variables and one of their five hypothesized domains of influence: Safety, on parental environmental perceptions: perceptions of the traffic safety and neighbourhood walking environment, as they associate with the walking (versus driven in a private vehicle).

\section{Parents' Perception of Traffic Safety}

Parents' perception of traffic safety demonstrated no significant correlation with walking (versus driven in a private vehicle), at 0.05 significance level. Parents, who agreed to the survey statements regarding heavy and fast moving traffic near home child's school in the morning and too many busy streets crossing on the route to/from school, had negative perception of traffic 
safety in their neighbourhood, but this perception was not associated with the likelihood to them allowing their child to walk to school.

Intersection density, distance between school and home, and presence of major road crossing on child's route to school were negatively correlated with parents' perception of traffic safety. As their relationship has never been studied before, this finding also uniquely contributes to the understanding of children's school travel behaviour. Rather surprising findings were nonsignificant association of absolute number of traffic counts around child's school in the morning and presence of traffic calming devices with parents' perception of safety.

\section{Parental Perception of Neighbourhood Walking Environment}

A significantly positive correlation was found between parental perception of neighbourhood walking environment and children's odds of walking to school. Parents who reported to have major barriers/obstacles, and inadequate amount of sidewalks that made it hard to get from place to place, had a negative perception of walking environment in their neighbourhood. It further reduced the likelihood of parents allowing their child to walk to school.

The model also reported significant correlations between several objectively measured built environment variables and parents' perception of walking environment. Length of missing sidewalks per route kilometer and distance between home and school were found to be negatively correlated, but intersection density was positively correlated with the perception of neighbourhood walking environment. However, both presence of retail density and major road crossings on the route to school had non-significant association with the perception of 


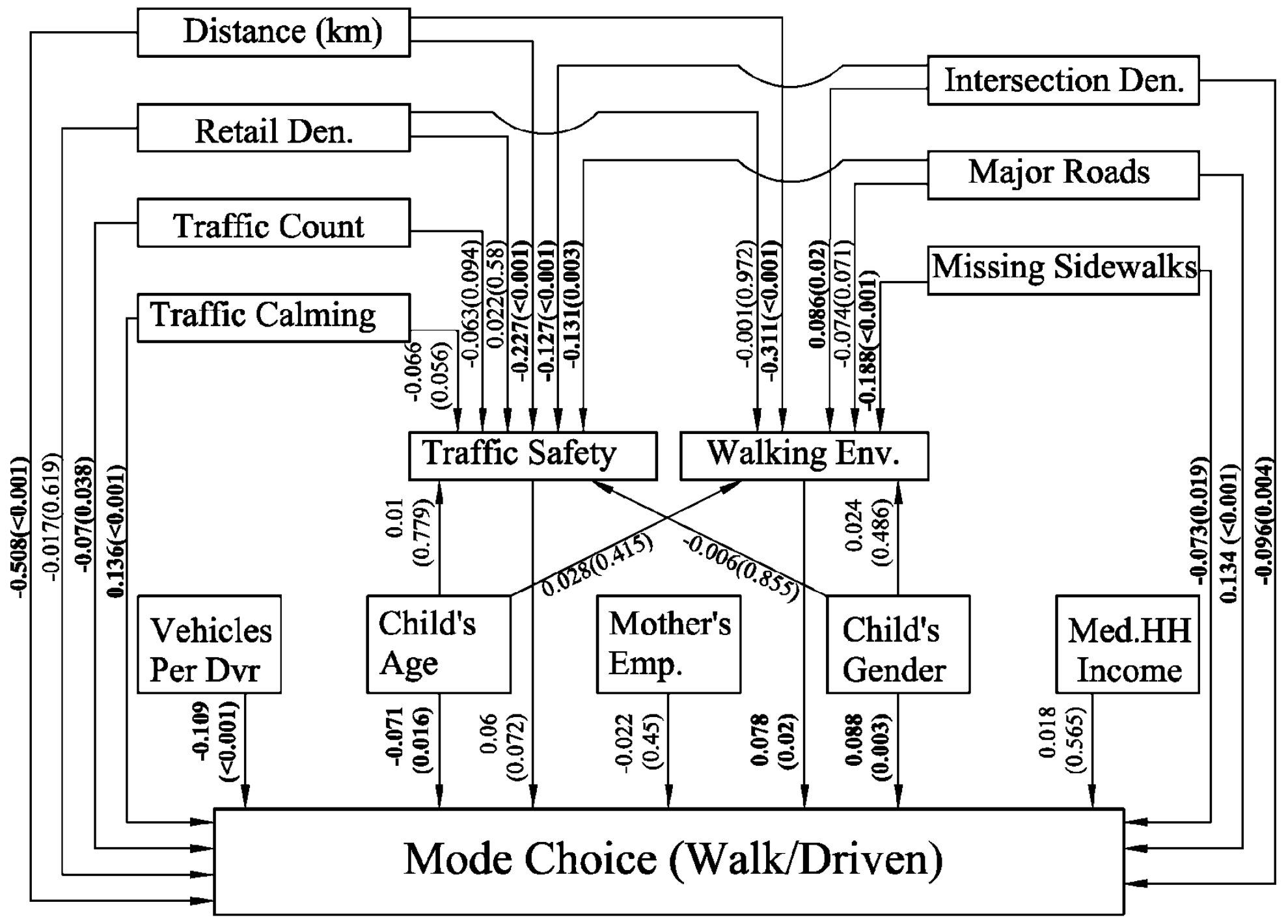

\section{Figure 4.4: Final Model Outputs}

Note: The numbers in parentheses are p-values. The numbers outside of parentheses are standardized direct effects (regression weights). Highlighted numbers are significant at the 0.05 level. 
neighbourhood walking environment. These findings produce unique insights and new knowledge with regards to relationship between the built environment and parental perceptions of the neighbourhood environment.

\subsubsection{School travel mode choice and Neighbourhood Built Environment}

Several objectively measured built environment variables were found to be significant in their direct correlation with walking (versus driven in a private vehicle), while controlling for their indirect influence through latent parental perceptions variables. Distance from child's home to school had strongest negative correlation with mode choice. Similarly, length of missing sidewalks per route kilometer, major road crossings, intersection density, and traffic count around school in the morning was also significantly negatively correlated with the mode choice variable. The model reported a positive significant correlation between presence of traffic calming devices on the route to school and the mode choice variable, which was anticipated. The presence of major road crossings on the route to school was found to be positively correlated with walking (versus driven in a private vehicle). Literature presents mixed association of retail density with walking or driving behaviour, but this study found no significant correlation between them.

Most of the built environment variables were constituently associated with the mode choice variable for both boys and girls. However, length of missing sidewalk per route kilometer and morning traffic count near school was significantly correlated with the mode choice in the case of boys but not for girls. 


\subsection{Discussion}

Drawing on Mitra's (2013) BMST framework, current study hypothesized that objective built environment and sociodemographic characteristics directly influence parental subjective perceptions, which affect their decision about child's school travel mode choice. In particular, the study focused on the association between built environment characteristics and parental perceptions of traffic safety and neighbourhood walking environment, in regards to child's school transportation mode choice. In addition to influencing parental perceptions, the objective built environment characteristics were also allowed to directly interact with the mode choice variable. If their direct association is the dominant one, then the observed relationship between the built environment and travel behaviour may be attributable to some other perceptions, perhaps four remaining domains-proximity, connectivity, comfort, and attractiveness, as outlined in the BMST framework.

\subsubsection{School travel mode choice and Sociodemographic characteristics}

The statistical results did not provide sufficient evidence to conclude the hypothesis that sociodemographic characteristics influence parents' mode choice decision. Child's gender, age, and number of vehicles per licenced driver were found directly related to the mode choice. Boys were found to be more likely to walk to school than girls. However, some difference was observed between boys' and girls' school travel mode choice decisions. For girls, higher intersection density on the route to school, and number of vehicles per licensed driver reduced their likelihood of walking to school, but both factors were non-significant for boys. However, for boys missing sidewalks and higher traffic count on the route to school appeared to deter their odds of walking, which were not found significant in girls (See Appendix ' $A$ ' for gender 
based model outputs). Many studies have found similar association between child's gender and the likelihood to walk to school, but in different study setups (Carver et al., 2014). Higher rates of walking to school among boys may reflect social tendencies of parents to be more protective of girls and to place greater restrictions on girls' independent mobility. Existing literature points that from early childhood parents encourage boys over girls to take risks (Morrongiello and Dawber, 1999), so traffic concerns may provide a greater deterrent to girls walking/cycling. At the same time, sex differences in general levels of physical activity may also explain such differences.

\subsubsection{Neighbourhood Built Environment and Parental Perceptions}

This study also examined the interaction between objectively measured built environment and parental perceptions of traffic safety and neighbourhood walking environment, as they relate to a child's school travel decision processes. Results indicate that perception of walking environment played a significant in influencing children's odds of walking to school; however, parental perception of traffic safety was not significantly correlated with walking. It was also found that parents' subjective views of the neighbourhood environment, particularly those related to traffic and pedestrian safety, were not always consistently related to the objective built environment characteristics.

\section{Neighbourhood Built Environment and Parental Perception of Traffic Safety}

In a rather counterintuitive finding, major road crossings appeared to improve the likelihood of walking in their observed direct correlation with the mode choice, which is not consistent with other studies such as Bringolf-Isler et al., (2008); Emond \& Handy, (2012); and Larsen et al. (2012). However, parents perceived major road crossing on the route to school as a significant 
barrier and risk to traffic related safety. Although not observed in this study, but one explanation to such observed finding could be that the presence of signals at major road crossings might be helpful in moving safely through the intersection. At the same time, parents perceive their children's proximity to large volume of high speed traffic as a negative element. Nonetheless, this finding points to the importance of well-designed signalized crossings, in order to mitigate the perceived negative impact of proximity to the traffic.

Similarly, contrary to an expected negative association, morning traffic counts around the school were not significantly associated with parental perception of traffic safety. Traffic calming devices on the route to school also did not significantly associate with parental perception of traffic safety as one might expect. A couple of explanations might help explain this unusual relationship. First, parental perceptions are very subjective in nature and might not directly relate to objectively measured environment. For example, parents might perceive a street with high traffic count as safe as long as there are no or little traffic related injuries. As this study did not include data on traffic related injuries, further analysis is required to test this statement. Secondly, stated concerns around traffic safety can be a way for parents to justify their choice of driving children to school, regardless of the actual traffic conditions. Nonetheless, the odds of walking were reduced in the neighbourhoods with high traffic counts around school. However, the rate of children walking increased in neighbourhoods where traffic slowing measures were taken. This finding highlights disconnection between objective and subjective nature of perceptions in general. Although traffic calming devices appear to work as intended in improving the odds of walking, but such engineered environment may not 
be well received by the neighbourhood residents and fails to appropriately address parents' subjective expectations of an adequately supportive and safe neighbourhood environment.

\section{Neighbourhood Built Environment and Parental Perception of Walking Environment}

Parental perceptions of walking environment, were more reflective of the built environment of a neighbourhood. For example, length of missing sidewalks and distance from school to home had negative impact on the perception of walking environment and the odds of walking. These results imply that parents were more likely to allow their child to walk to school if they perceived higher sidewalk coverage on the route to school, as well as short distance between home and school. However, intersection density on the route to school showed overriding tendencies in its direct and mediated influence on walking (versus driven in a private vehicle). Intersection density appears to be positively influencing parental perceptions of walking environment, but its direct negative correlation with walking (versus driven in a private vehicle) suggests presence of other factors that may be influencing parental perceptions. A possible explanation for this finding could be that although street connectivity provides route directness (Dalton et al., 2011; de Vries et al., 2010; Panter et al., 2010a), but at the same time it also presents the potential for more and fast moving traffic, as well as more street crossings (GilesCorti et al., 2011; Sirard \& Slater, 2008), which is perceived as a significantly traffic safety risk by the parents, whereby reducing children's odds of walking to school. 


\subsection{Summary of new findings:}

In response to the research question, findings of this study provide new insight into the correlation between built environment, parental perceptions, sociodemographic variables, and children's school travel mode choice. Amongst sociodemographic characteristics, gender, age and number of vehicles available per licenced driver were key factors that related with choice to walk to school, but there was no sufficient evidence to conclude that sociodemographic characteristics influence parents' mode choice decision. Parental perception of the neighbourhood walking environment was also found to play a noteworthy role in the mode choice decision making process. However, the perception of traffic safety had no effect on walking (versus driven in a private vehicle) to school. It was also found that parents' subjective views of the neighbourhood environment, particularly those related to traffic and pedestrian safety, were not always consistently related to the objective built environment characteristics. Contrary to an expected negative association, traffic calming devices and heavy morning traffic count around school were found to be insignificantly correlated with parents' perception of traffic safety. However, traffic calming devices directly facilitated walking and morning traffic count around school emerged as a strong direct barrier to the likelihood of walking to school. Similarly, despite of their negative correlation with parental perceptions of traffic safety, major road crossings were found to be facilitating walking in their direct association with mode choice variable. On the other hand, parents perceived intersection density as a facilitator of children's walk to school, even if it was negatively correlated with odds of walking (versus driven in a private vehicle) in its direct association. These findings highlight disconnection between objective and subjective nature of perceptions in general. 


\section{Chapter 5: Implications for Policy}

This study adds new knowledge to the existing literature on the correlates of Active School Transportation (AST). First, it improves theoretical understanding of how built environment indirectly influences children's school travel behaviour through mediation of parental perceptions of neighbourhood environment. Parents first perceived the problems in the neighbourhood built environment before deciding whether their child would walk or be driven to school. Second, parental subjective views of the neighbourhood environment, particularly those related to traffic and pedestrian safety, were not always consistently related to the objective built environment characteristics. While parental perception of walking environment were found to play an important role, parental perception of traffic safety was insignificant in deciding their child's school travel mode choice. It is evident from the findings that AST mode choice is a multilevel and complex process that may requires physical as well as programming level changes. To delineate policy implications based on these findings, it is first important to understand the City of Toronto's existing in-effect framework that facilitates children's walking to school.

\subsection{Review of existing policy framework in Toronto}

City of Toronto Official Plan (OP) recognizes the importance of walking and advocates for creating a built form and urban environment conducive to walking and fosters safe, comfortable and attractive facilities for walking throughout the city (City of Toronto, 2009b). Secondary plans further reinforce OP's vision on pedestrian friendly conditions, safety and walkability in general. Toronto Walking Strategy (2009a) lays out a set of action items to provide leadership, support, and promote walking culture by establishing an integrated walking 
network (City of Toronto, 2009b). Most recently, the City council agreed to develop Complete Streets Guidelines that will help ensure routine consideration of Complete Streets, which are safe and convenient for all users including pedestrians, bicyclists, and motorists, during the construction, reconstruction, and maintenance of all city streets (CSFC, 2012).

Toronto District School Board (TDSB) recently adapted a charter for safe and sustainable transportation (TDSB, 2013). At this point, the document merely outlines TDSB's commitment to invest in resources that support active, safe and sustainable transportation by identifying and removing barrier to and from school. The document also appears to be promising as TDSB ensures developing school travel plans and road safety education within schools and by partnering with stakeholders to work as a coordinated team. Among other goals of this charter is to increase students' overall physical activity and mental health through positive interactions with peers, parents, and staff (TDSB, 2013). However, no further information is available about implementation of this document.

In 2007, Green Communities Canada, in partnership with Public Health Agency of Canada, introduced a community based- School Travel Planning (STP) - approach, in four provinces across Canada. STP deals with travel-related issues at school by combining international best practices into a process and creating Canada specific tools. Amongst the main objectives of the STP model is to promote active and sustainable modes of school travel for students and families by partnering with schools, municipalities, public health units and community groups (GCC, 2013). Metrolinx, a provincial transportation authority for the GTHA, led 'Stepping It Up' pilot program from 2009 to 2011, in partnership with Green Communities Canada and funded by Transport Canada, to introduce STP initiative in 71 elementary schools in Ontario (Metrolinx, 
2014). Metrolinx recently conducted an analysis of 19 schools where the STP model was implemented. The findings of the Metrolinx (2014) report highlight that a behaviour change was noticeable. Not only the rates of walking and physical activity increased, but the model potentially reduced vehicle kilometers travelled, greenhouse gas emission, and air pollutants at a petty amount of cost. However, Buliung et al. (2011), based on their pilot evaluation of the STP in 4 Canadian provinces, showed only a modest increase in AST rates and suggested changes to the STP model, in order to address recent research on the AST mode choice process. Although, Green Communities Canada continues to implement the STP model in various other municipalities throughout Canada, but in the absence of a longer-term revenue stream, Metrolinx formally ended its pilot program in the GTA after 2011. At this point, Metrolinx continues to support walking, cycling and transit use for school transportation through community mobilization.

\subsection{Recommendations}

As discussed earlier in this paper, it is evident from the findings of this study that AST mode choice is a multilevel and complex process that may requires physical as well as programming level changes. However, review of the existing policy framework reveals that although City of Toronto is administrating multiple strategies promoting walking behaviour, but almost all of these address adults' mobility needs. With regards to school level programing, studies evaluating the STP model suggest that the effect of this intervention on behavioural changes has remained modest at best. Furthermore, the role of local municipal administration with regards to implementing STP model in local schools is unclear. In order to increase uptakes of children walking to school, following recommendations argue in favour of a collective action-in 
the form of school level programs founded in a new children specific pedestrian and bicyclist policy-undertaken by both the City and the school boards. The City should take a lead and leverage this opportunity when both the City and the TDSB are in the process of revising their existing regulations or adapting new policies that encourage walking.

\subsubsection{Need for a children specific pedestrian and bicyclist action plan}

Many states in the US have adapted region wide(the Clark County, the Puget Sound region to name a few) active transportation master plans that guide further investment in improving active transportation infrastructure and programming for both adults and children ensuring that they move safely through neighbourhoods. In the Canadian context, Board of Health for the City of Ottawa Health Unit has partnered with City's Transportation committee and Council to draft a school based active transportation plan that fosters the development of healthy, active communities through Complete Street Policy and reduction in aggressive driving behaviour (Levy, 2013).

Learning from international and Canadian examples, City of Toronto should consider adapting a children specific pedestrian and bicyclist action plan, in order to promote children's walking as an important measure of their health and vitality. The key goal of the action plan would be to ensure that children's AST can co-exist with other modes of travel by making it a safer, more comfortable and convenient way to travel. Such action plan would be a citywide policy, comprehensive in scope addressing engineering, education, enforcement, and evaluation by ensuring City's commitment to : 
- Update its existing ordinances and policies, such as Walking Strategy (2009), Complete Streets guidelines, and other related regulations to conform to children's mobility needs.

- Encourage further research on the relatively unknown relationship between engineered streetscape and perceptions, in order to improve and update its policies and minimize disconnect between the perceived and engineered built environment.

- Make school level programming (similar to the STP model) mandatory, whereby requiring schools to collaborate with local residents and other stakeholder to develop neighbourhood level master plans that identify barriers to AST, run programs that encourage AST, and educate parents and children.

- Provide consistent funding sources for school level programming such as STP by partnering with Public Health Canada or other stakeholders that have vested benefits in the health and well-being of Canadian children.

Arguably, as a City led top-down policy, children specific pedestrian and bicyclist action plan could ensure effectiveness, consistency, and coordination in efforts aiming to increase AST rates in Toronto.

\subsubsection{Programming at the school level}

As mentioned earlier, it is expected that the City and the school boards would work hand in hand, in order to bring significant changes to children's school travel behaviour. The citywide children specific pedestrian and bicyclist action plan, as described previously, would set the stage for interventions by providing policy background, whereas school board level programming would require the schools to take ownership and implement by collaborating 
with local community and other stakeholders. Literature informs that schools play an important role in fostering walking behaviour amongst children.

Since the aforementioned proposed action plan would require all schools in Toronto to participate in local level programming, the TDSB should develop its program while implementing the new charter for safe and sustainable transportation (2013), or may wish to adapt already developed the STP model. Nevertheless, the key goals of schools level programming would be:

- To collaboration with neighbourhood residents and other stakeholders and develop local level master plans identifying neighbourhood wide issues and barriers for children walking to school. Eventual purpose of a local level master plan would be to help the City develop a community specific solution to the problem, whereby minimizing gap between perceived and engineered built environment.

- To run social interventions encouraging parents and children to walk or bike to school. For example, in suburban neighbourhoods, where distance from home to school reduces the odds of walking, the school may encourage parents to drop their children on the periphery of safe zone around school, which the school might have established in collaboration with parents. On the other hand, sites for new schools in new neighbourhood should be chosen to assure that barriers to walking and biking to school are adequately addressed during the design phase of the neighbourhood. Similarly, in order to increase physical activity skills that will last a lifetime, schools may adapt programs specifically targeting female students in collaboration with parents who may encourage them to walk to school at the home end. 
- To educate parents and children to address the social and psychological barriers families face in adopting walking and bicycling as a routine. For example, parents' exaggerating perceptions might undermine their child's odds of walking in an otherwise supportive physical environment. Educating parents in such case could bring effective results than devising physical changes.

Nonetheless, learning from existing evaluations of initiatives like STP (e.g. Buliung, 2011), the school level programing should must ensure to accommodate new and emerging perspectives on children's AST. 


\section{Chapter 6: Conclusion}

This study analysed school travel behaviour of $n=720$ grade 5 and 6 children in Toronto, using structural equation modelling approach to administrated survey responses (from children and their parents), GIS measures of built environment, and sociodemographic variables. Findings of this study provide new evidence regarding the relationship between built environment, parental perceptions of traffic safety and neighbourhood walking environment, and children's school travel behaviour. Parents perceived problems in the neighbourhood environment before taking decisions about their child's school travel mode choice. However, parental perceptions of the neighbourhood environment, especially those related to traffic safety, were not always consistently related to the objective built environment characteristics. It is evident from the findings that AST mode choice is a multilevel and complex process that may requires physical as well as programming level changes. However, current City policies and school level programs don't appear to be effective in addressing these emerging issues with regards to children school travel behaviour. Collective interventions, such as new school level programs founded in new City level children specific pedestrian and bicyclist action plan, involving the City, the school boards, parents, and other stakeholder could prove to be more successful in increasing the AST uptake amongst young school-going children.

\subsection{Limitations}

Despite of providing new evidences, this study has several limitations. The scope of this study was limited to an examination of the objectively measured and perceived neighbourhood environment related only to a child's school travel route. Previous research has indicated the importance of many other aspects of the built environment; both engineered and perceived, 
which could not be addressed in this research. Furthermore, this study did not examine correlation between the two parental perception variables (perception of traffic safety, perception of walking environment). It is quite possible that they might be correlated; however, the results and findings do not reflect their potential association. This study also did not explore parental attitudes towards AST and role of children's perceptions as they relate to their school travel behaviour. Therefore, while the findings of this study may illustrate relationship between built environment and parental perceptions of traffic safety and walking environment, any direct effects of the built environment characteristics on the odd of walking (versus driven in a private vehicle) might be residuals of perceptions and parental attitudes not included in the analysis. Nonetheless, results of this research suggest that there is a potential in exploring link between built environment and individual's psychological and social behaviour, as they relate to AST. Further research is required to accurately establish correlates of AST including parental attitude and perceptions, and children's perceptions of the neighbourhood environment. Besides, a continued research perspective is necessary for suggested interventions to be successful. 


\section{Appendix 'A': Additional Model Outputs}

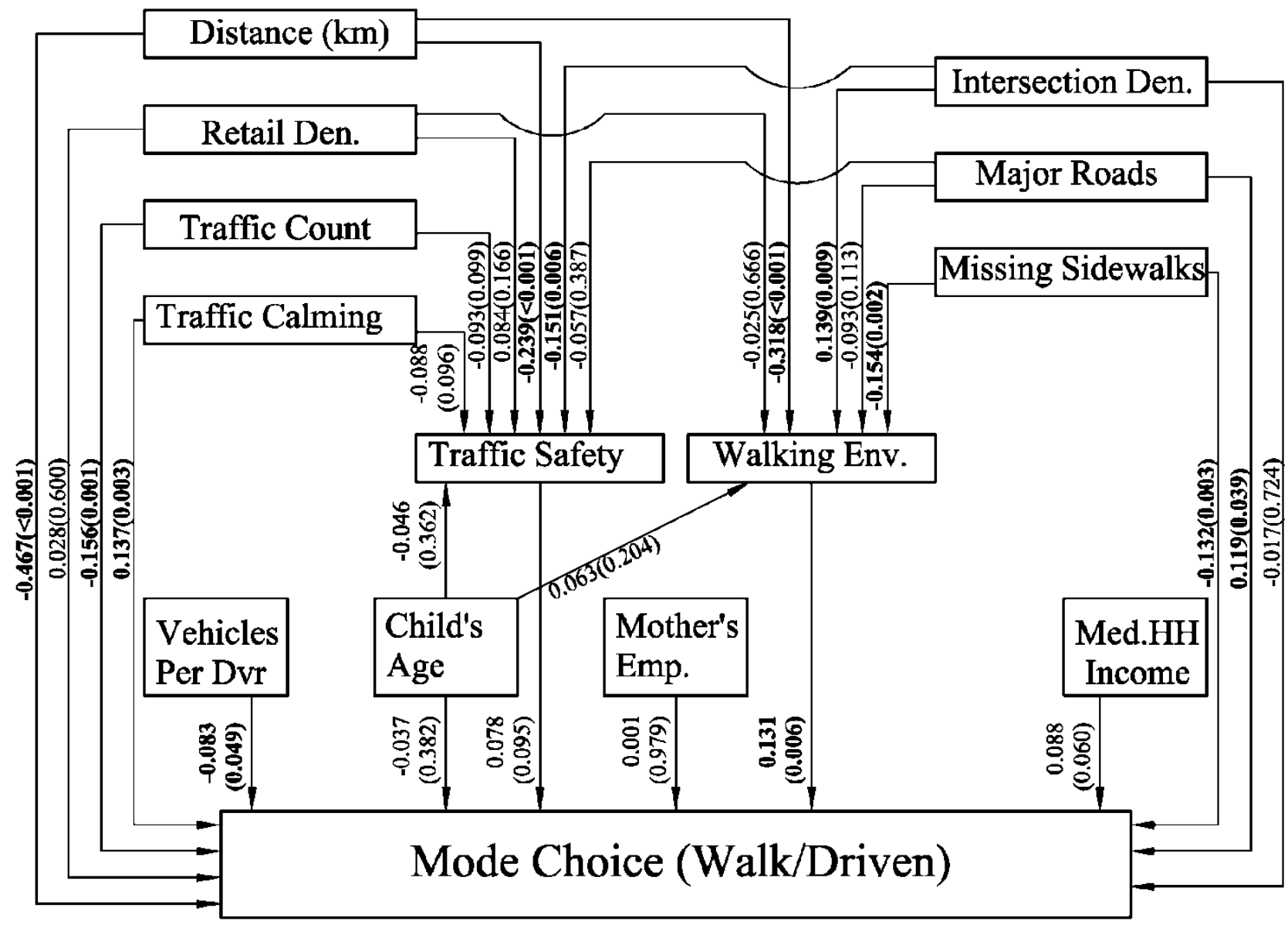

Figure A.1: Mode Outputs- For Boys

Note: The numbers in parentheses are $p$-values. The numbers outside of parentheses are standardized direct effects (regression weights). Highlighted numbers are significant at the 0.05 level. 


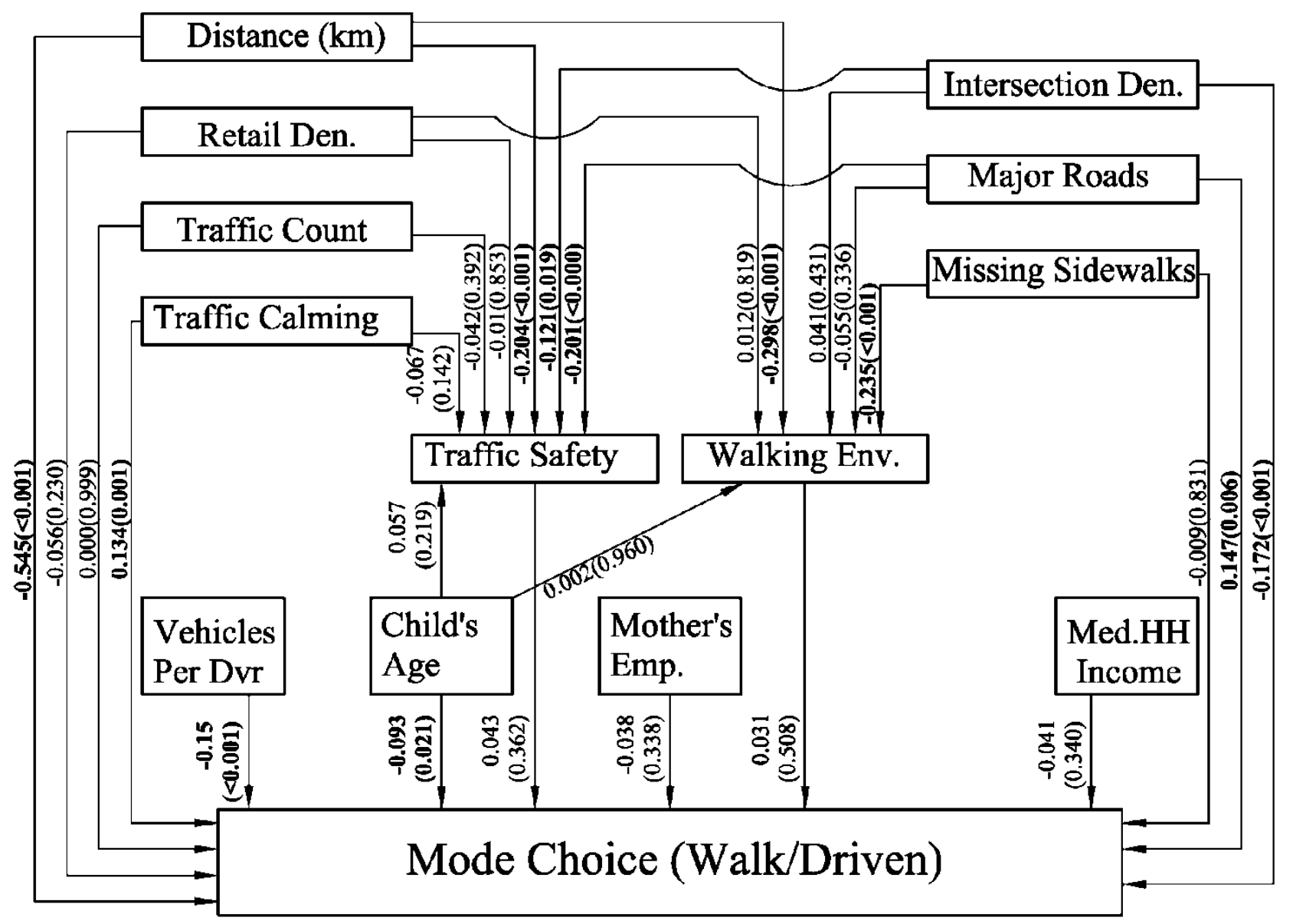

Figure A.2: Mode Outputs- For Girls

Note: The numbers in parentheses are $p$-values. The numbers outside of parentheses are standardized direct effects (regression weights). Highlighted numbers are significant at the 0.05 level. 


\section{References}

AHKC [Active Healthy Kids Canada]., (2012). 'The 2012 Active Healthy Kids Canada Report Card on Physical Activity for Children and Youth.' Retrieved on Dec. 23, 2013 from http://www.activehealthykids.ca/ReportCard/PhysicalActivity.aspx

Al Mamun, A., Cramb, S.M., O'Callaghan, M.J., Williams, G.M., Najman, J.M., (2009). 'Childhood overweight status predicts diabetes at age 21 years: a follow-up study.' Obesity, (17): 1255-1261.

Anderson, T.W., Amemiya, Y., (1998). 'The asymptotic normal distribution of estimators in factor analysis under general conditions.' Ann. Stat. 16(2), 759-771.

Babey, S.H., Hastert, T.A., Huang, W., \& Brown, E.R., (2009). 'Sociodemographic, family, and environmental factors associated with active commuting to school among US adolescents.' Journal of Public Health Policy, (30): S203-S220.

Bandura, A., (1986). 'Social foundations of thought and action: A social cognitive theory.' Prentice Hall, Englewood Cliffs, NJ.

BEAT [ Project Built Environment and Active Transportation], (2010). 'Summary Report of Study 2 Findings of School Travel Behaviour of Grade 5 and 6 students in Toronto, Canada.' Retrieved on February15, 2014 from http://physical.utoronto.ca/docs/project-beatdocuments/BEAT_Summary_Report_for_Schools-_July_5_2012.pdf?sfvrsn=0

Bentler, P.M., Dudgeon, P., (1996). 'Covariance structure analysis: statistical practice, theory, and directions.' Annu. Rev. Psychol. 47, 563-592.

Bhatt, C.R., Koppelman, F.S., (2003) "Activity-Based Modeling of Travel Demand". In R. Hall (Ed.), (pp. 39-65) Springer US.

Black, C., Collins, A., \& Snell, M., (2001). 'Encouraging walking: The case of journey-to-school trips in compact urban areas.' Urban Studies, 38(7): 1121-1141.

Buliung, R.N., Mitra, R., \& Faulkner, G.E.J., (2009). 'Active school transportation in the Greater Toronto Area, Canada: An exploration of trends in space and time (1986-2001).' Preventive Medicine, 48(6): 507-512.

Buliung, R., Faulkner, G. E. J., Beesley, T., Kennedy, J., (2011). 'School Travel Planning: Mobilizing School and Community Resources to Encourage Active School Transportation.' Journal of School Health, 81(11), 704-712.

Bürgi, F., Meyer, U., Granacher, U., Schindler, C., Marques-Vidal, P., Kriemler, S., Puder, J.J., (2011). 'Relationship of physical activity with motor skills, aerobic fitness and body fat in preschool children: a cross-sectional and longitudinal study (Ballabeina)'. International Journal of Obesity, 35(7):937-44.

Bringolf-Isler, B., Grize, L., Mader, U., Ruch, N., Sennhauser, F.H., Braun-Farhlander, C., \& SCARPOL

Team., (2008). 'Personal and environmental factors associated with active commuting to school in

Switzerland.' Preventive Medicine, (46): 67-73.

Byrne, B.M., (2010). 'Structural Equation Modeling with AMOS: Basic Concepts, Applications, and Programming-Second Edition.' New York: Routledge. 
Cao, X., Mokhtarian, P. L., \& Handy, S. L., (2009). 'No particular place to go: An empirical analysis of travel for the sake of travel. Environment and Behavior.' (41): 233-257.

Carver,A., Panter, J.R., Jones, A.P., van Sluijs E.M.F., (2014) (Article in Press). 'Independent mobility on the journey to school: A joint cross-sectional and prospective exploration of social and physical environmental influences', http://dx.doi.org/10.1016/i.jth.2013.12.003i.

Cervero, R., \& Kockelman, K., (1997). 'Travel demand and the 3Ds: Density, diversity, and design.' Transportation Research Part D, 2(3): 199-219.

CHASS, (2013). 'Canadian Census Analyser-2011 National Household Survey (NHS) Profiles Files / Profile of Census Disseminations Areas'. Retrieved on January 15, 2014 from http://dc1.chass.utoronto.ca.ezproxy.lib.ryerson.ca/cgibin/census/2011nhs/displayCensu s.cgi?year $=2011 \&$ geo $=$ da.

City of Toronto, (2009a). 'Toronto Walking Strategy.' Retrieved on March 12, 2014 from http://www1.toronto.ca/City\%200f\%20Toronto/Transportation\%20Services/Walking/File s/pdf/walking-strategy.pdf.

City of Toronto, (2009b). 'Official Plan policies relevant to the walking strategy-Appendix A.'

Retrieved on March 12, 2014 from

http://www1.toronto.ca/City\%200f\%20Toronto/Transportation\%20Services/Walking/File s/pdf/appendix op policies.pdf

City of Toronto, (2009c). 'Existing Pedestrian Policies, Programs and Actions.' Retrieved on March 12, 2014 from

http://www1.toronto.ca/City\%200f\%20Toronto/Transportation\%20Services/Walking/File s/pdf/pedestrian-policies-programs-matrix.pdf

Collins, D. C. A., and R. A. Kearns., (2002). 'The Safe Journeys of an Enterprising School: Negotiating Landscapes of Opportunity and Risk.' Health and Place 7, 293-306.

Cooper, A.R., Page, A.S., Foster, L.J., \& Qahwaji, D., (2003). 'Commuting to school: Are children who walk more physically active?' American Journal of Preventive Medicine, 25(4): 273276.

Copperman, R.B., \& Bhat, C.R., (2010). 'An assessment of the state-of-the-research of US children's timeuse and activity-travel patterns.' Retrieved on Dec. 28, 2013, from http://www.ce.utexas.edu/prof/bhat/ABSTRACTS/Assess of State of Research of Child rens Nov2010.pdf

CSEP [Canadian Society for Exercise Physiology], (2011). 'Canadian Physical Activity and Sedentary Behaviour Guidelines Handbook.' Retrieved on Dec. 23, 2013 from http://www.csep.ca/CMFiles/Guidelines/CSEP Guidelines Handbook.pdf

CSFC [Complete Streets for Canada], (2012). 'Toronto approves the scoping of Complete Streets Guidelines.' Retrieved on March 18, 2014 from http://completestreetsforcanada.ca/news/toronto-approves-scoping-complete-streetsguidelines

Dalton, M.A., Longacre, M.R., Drake, K.M., Gibson, L., Adachi-Mejia, A.M., Swain, K., Xie, H., \& Owens, P.M., (2011) 'Built environment predictors of active travel to school among rural adolescents.' American Journal of Preventive Medicine, 40(3), 312-319. 
Daly-Smith, A.J.W.,McKenna, J., Radley, D. Long, J., (2011). 'The impact of additional weekdays of active commuting to school on children achieving a criterion of $300+$ minutes of moderate-to- vigorous physical activity.' Health Education Journal, 70(4): 428-434.

de Vries, S.I., Hopman-Rock, M., Bakker, I., Hirasing, R.A., \& van Mechelen, W., (2010). 'Built environment correlates of walking and cycling in Dutch urban children: Results from the SPACE study. International' Journal of Environmental Research and Public Health, (7): 2309-2324.

Emond, C.R., \& Handy, S.L., (2012). 'Factors associated with bicycling to high school: Insights from

Davis, CA.' Journal of Transport Geography, (20): 71-79.

Ewing, R., Schroeer, W., \& Greene, W., (2004). 'School location and student travel: Analysis of factors affecting mode choice.' Transportation Research Record, 1895: 55-63.

Ewing, R., Cervero, R., (2010). 'Travel and the built environment.' Journal of the American Planning Association, 76(3): 1-30.

Faulkner, G.E.J., Richichi, V., Buliung, R., Fusco, R., \& Moola, F. (2010). 'What's "quickest and easiest?"

Parental decision making about school trip mode.' International Journal of Behavioural Nutrition and Physical Activity, (7):62.

Ferreira, I., van der Horst, K., Wendel-Vos, W., Kremers, S., van Lenthe, F.J., Brug, J., (2007). 'Environmental correlates of physical activity in youth - a review and update.' Obesity Rev. (8): 129-154.

GCC [Green Communities Canada]., (2013).' Active and Safe Routes to School.' Retrieved on March 12, 2014 from http://www.saferoutestoschool .ca/.

Giles-Corti, B., Donovan, R. J. (2003). 'Relative influences of individual, social environmental, and physical environmental correlates of walking.' American Journal of Public Health, 93: 1583-1589.

Giles-Corti, B.,Wood, G., Pikora, T., Learnihan, V., Bulsara, M., Van Niel, K., Timperio, A., McCormack, G., \& Villanueva, K., (2011).' School site and the potential to walk to school: The impact of street connective and traffic exposure in school neighborhoods.' Health \& Place, 17, 545-550.

Glanz, K., Rimer, B.K., Viswanath, K. (Eds.)., (2008). 'Health behavior and health education: Theory, research, and practice (4th ed.).' San Francisco, CA: Jossey-Bass.

Golob T. F., (2003). 'Structural equations modeling for travel behaviour research.' Transportation Research, Part B, 37(1), 1-25.

Handy, S.L., Cao, X., Mokhtarian, P.L., (2006). 'Does self-selection explain the relationship between built environment and walking behavior? Empirical evidence from Northern California.' Journal of the American Planning Association, 72(1): 55-74.

Haukka, E., Ojajarvi, A., Takala, E.P., Viikari-Juntura, E., Leino-Arjas,P., (2012). 'Physical workload, leisure time physical activity, obesity and smoking as predictors of multi-site musculoskeletal pain.A2 year prospective study of kitchen workers.' Occupational and Environmental Medicine (69): 485-492.

Kaplan, D., (2000). 'Structural Equation Modeling. Foundations and Extensions.' Thousand Oaks: Sage Publications,. 
Kerr, J., Rosenberg, D., Sallis, J.F., Saelens, B.E., Frank, L.D., Conway, T.L., (2006).' Active commuting to school: associations with environment and parental concerns.' Medicine and Science in Sports and Exercise. (38):787-794.

Lang, D., Collins, D., Kearns, R., (2011). 'Understanding modal choice for the trips to school.' Journal of Transport Geography, (19): 509-514.

Larsen, K., Gilliland, J., Hess, P., Tucker, P., Irwin, J., \& He, M., (2009). 'The influence of the physical environment and socio-demographic characteristics on children's mode of travel to and from school.' American Journal of Public Health, 99(3): 520-526.

Larsen, K., Gilliland, J., \& Hess, P.M., (2012). 'Route-based analysis to capture the environmental influences on a child's mode of travel between home and school.' Annals of the Association of American Geographers, 102, 1-18.

Lei, M., Lomax, R.G., (2005). 'The effect of varying degrees of nonnormality in structural equation modeling.' Structural Equation Model. 12(1), 1-27.

Levy, I. (2013). 'Healthy eating active living strategy update: school-based active transportation.' Retrieved on March 12, 2014 from http://ottawa.ca/calendar/ottawa/citycouncil/obh/2013/10-21/SAT\%20Report.pdf.

Lin, J., Chang, H., (2010). 'Built environment effects on children's school travel in Taipei: Independence and travel mode.' Urban Studies, 47(4): 867-889.

McDonald, N.C., (2008). 'Household interactions and children's school travel: The effect of parental work patterns on walking and biking to school.' Journal of Transport Geography, 16(5): 324-331.

McMillan, T.E., (2005). 'Urban form and a child's trip to school: The current literature and a framework for future research.' Journal of Planning Literature, 19(4): 440-456.

McMillan, T.E., (2007). 'The relative influence of urban form on a child's travel mode to school.' Transportation Research Part A, 41(1):69-79.

Metcalf, B., Voss, L., Jeffery, A., Perkins, J., Wilkin, T., (2004). 'Physical activity cost of the school run: impact on school children of being driven to school.' British Medical Journal, 329(7470):832-833.

Metrolinx, (2014). 'The Costs and Benefits of School Travel Planning Projects in Ontario, Canada.' Retrieved on March 12, 2014 from http://metrolinx.com/en/projectsandprograms/schooltravel/Costs and Benefits of Sch ool Travel Planning Projects EN.pdf.

Mitra, R., Buliung, R., Roorda, M.J., (2010). 'The built environment and school travel mode choice in Toronto, Canada.' Transportation Research Record, 2156, 2150-2159.

Mitra, R., Buliung, R., (2012). 'Built environment correlates of active school transportation: Neighborhood and the modifiable areal unit problem.' Journal of Transport Geography, (20): 51-61.

Mitra, R., (2013).'Independent mobility and mode choice for school transportation: a review and framework for future research.' Transportation Review, 33(1):21-43.

Morrongiello,B.A.,Dawber,T.,(1999).'Parental influences on toddler's injury risk behaviors: are sons and daughters socialized differently.' Journal of Applied Development Psychology. 20 (2),227-251. 
Mueller, R.O., (1996) 'Basic Principles of Structural Equation Modeling - An Introduction to LISREL and EQS.' New York: Springer-Verlag Inc.

Nelson, N.M., Foley, E., O'Gorman, D.J., Moyna, N.M., \& Woods, C.B., (2008). 'Active commuting to school: How far is too far?' International Journal of Behavioral Nutrition and Physical Activity, 5(1).

Panter, J.R., Jones, A.P., Van Sluijs, E.M.F., (2008). 'Environmental determinants of active travel in youth: A review and framework for future research.' International Journal of Behavioral Nutrition and Physical Activity, (5): 34

Panter, J.R., Jones, A.P., van Sluijs, E.M.F., \& Griffin, S.J., (2010a). 'Neighborhood, route, and school environments and children's active commuting'. American Journal of Preventive Medicine, 38(3), 268-278.

Panter, J.R., Jones, A.P., van Sluijs, E.M.F., \& Griffin, S.J., (2010b). 'Attitudes, social support and environmental perceptions as predictors of active commuting in school children.' Journal of Epidemiology and Community Health, (64): 41-48.

PHAC [Public Health Agency for Canada], (2013). 'What is Active Transportation?' Retrieved on Dec.22, 2013 from http://www.phac-aspc.gc.ca/hp-ps/hl-mvs/pa-ap/at-ta-eng.php

Pont, K., Jenny Z., David W., Sally B., and Rebecca A., (2009). 'Environmental correlates of children's active transportation: A systematic literature review.' Health \& Place (15):84962.

Rossen, L.M., Pollack, K.M., Curriero, F.C., Shields, T.M., Smart, M.J., Furr-Holden, C. DM., Cooley-Strickland, M., (2011). 'Neighborhood incivilities, perceived neighborhood safety, and walking to school among urban-dwelling children.' Journal of Physical Activity and Health, 8(2):262-71.

Sallis, J.F., Frank, L.D., Saelens, B.E., Kraft, M.K., (2004) 'Active transportation and physical activity: opportunities for collaboration on transportation and public health research.' Transport Research Part-A, 38(4):249-268.

Sallis, J.F., Owen, N.,\& Fisher, E.B., (2008). 'Ecological models of health behavior.' in K. Glanz, B.K. Rimer, K. Viswanath (Eds.), Health behavior and health education: Theory, research, and practice (4th ed.,pp. 466-485). San Francisco, CA: Jossey-Bass.

Schlossberg, M., Greene, J., Phillips, P.O., Johnson, B., \& Parker, B., (2006). 'School trips: Effects of urban form and distance on travel mode.' Journal of the American Planning Association, 72(3), 337-346.

Siervo, M., Ruggiero, D., Sorice, R., Nutile, T., Aversano, M., lafusco, M., Vetrano, F., Wells, J.C., Stephan, B.C., Ciullo, M., (2012). 'Body mass index is directly associated with biomarkers of angiogenesis and inflammation in children and adolescents.' Nutrition, (28): 262-266.

Sirard, J.R., Slater, M.E., (2008).'Walking and bicycling to school: A review.' American Journal of Lifestyle Medicine, 2(5): 372-396.

Southward, E.F., Page, A.S., Wheeler, B.W., Cooper, A.R., (2012). 'Contribution of the school journey to daily physical activity in children aged 11-12 years.' American Journal of Preventive Medicine, 43(2): 201-204.

Statistics Canada, (2013). 'Low income cut-offs (1992 base) before tax'. Retrieved on January 15, 2014 from http://www.statcan.gc.ca/pub/75f0002m/2012002/tbl/tbl02-eng.htm.

Stevens, J., (1996). 'Applied Multivariate Statistics for Social Sciences.' New Jersey: Lawrence Erlbaum Associates, Inc., Mahwah. 
Stewart, O., (2011). 'Findings from research on active transportation to school and implications for safe routes to school programs.' Journal of Planning Literature, 26(2), 127-150.

Sylvia-Bobiak, S., Caldwell, L. L. (2006). 'Factors related to physically active leisure among college students.' Leisure Sciences, 28: 73-89.

TDSB, (2013). 'TDSB Charter for Active, Safe and Sustainable Transportation.' Retrieved on March 12, 2014, from http://www.tdsb.on.ca/Portals/0/Community/docs/Active Transportation\%20Charter FI NAL.pdf.

Thompson, D.R., Obarzanek, E., Franko, D.L., Barton, B.A., Morrison, J., Biro, F.M., Daniels, S.R., Striegel-Moore, R.H., (2007).'Childhood overweight and cardiovascular disease risk factors: the national heart, lung, and blood institute growth and health study.' Journal of Paediatrics, (150):18-25.

Thompson, W. C., Aspinall, P., Montarzino, A. (2008). 'The childhood factor: Adult visits to green places and the significance of childhood experience.' Environment and Behavior, 40: 111143.

Timperio, A., Ball, K., Salmon, J., (2006). 'Personal, familial, social and environmental correlates of active commuting to school'. American Journal of Preventive Medicine, (30):45-51.

Tomporowski, P.D., Davis, C.L., Miller, P.H., Naglieri, J.A. (2008).'Exercise and Children's Intelligence, Cognition, and Academic Achievement.' Education Psychology Review, 20(2): 111-131.

Walker, J.L. (2001). 'Extended discrete choice models: Integrated framework, flexible error structures, and latent variables (PhD dissertation).' Massachusetts Institute of Technology. Retrieved Dec. 28, 2013, from http://transpor.epfl.ch/courses/dca2012/WalkerPhD.pdf

Wen, L.M., Fry, D., Rissel, C., Dirkis, H., Balafas, A., \& Merom, D. (2008). 'Factors associated with children being driven to school: Implications for walk to school programs.' Health Education Research, 23(2): 325-334.

Wilson, E.J., Marshall, J., Wilson, R., \& Krizek, K.J. (2010). By foot, bus or car: 'Children's school travel and school choice policy.' Environment and Planning A, (42): 2168-2185. 